\title{
SARS-CoV-2 N promotes the NLRP3 inflammasome activation to induce hyperinflammation
}

\section{Pan Pan \\ Jinan University \\ Miaomiao Shen \\ Wuhan University \\ Zhenyang Yu \\ Wuhan University \\ Weiwei Ge \\ Wuhan University \\ Keli Chen \\ Wuhan University \\ Mingfu Tian \\ Wuhan University \\ Feng Xiao \\ Wuhan University \\ Geng Li \\ Wuhan University \\ Zhenwei Wang \\ Wuhan Univerity \\ Jun Wang}

The Affiliated ShunDe Hospital of Jinan University

\section{Yaling Jia}

Wuhan University

\section{Wenbiao Wang}

Jinan University

\section{Pin Wan}

Wuhan University

Jing Zhang

Jinan University

\section{Weijie Chen}

Jinan University

Zhiwei Lei

Jinan University

Xin Chen 
Jinan University

Zhen Luo

Jinan University https://orcid.org/0000-0002-1142-2845

Qiwei Zhang

Southern Medical University https://orcid.org/0000-0002-2770-111X

\section{Meng Xu}

Jinan University

\section{Yongkui Li}

Jinan University

Jianguo Wu ( $\sim$ jwu898@jnu.edu.cn )

Jinan University

\section{Article}

Keywords: COVID-19, SARS-CoV-2, NLRP3 inflammasome, Cytokine storm, Nucleocapsid protein, Lung injury

Posted Date: November 11th, 2020

DOI: https://doi.org/10.21203/rs.3.rs-101224/v1

License: (c) (i) This work is licensed under a Creative Commons Attribution 4.0 International License. Read Full License

Version of Record: A version of this preprint was published at Nature Communications on August 2nd, 2021. See the published version at https://doi.org/10.1038/s41467-021-25015-6. 


\section{Abstract}

Excessive inflammatory responses induced upon SARS-CoV-2 infection interlocks with severe symptoms and acute lung injury in patients with Severe Coronavirus Disease 2019 (COVID-19). Revealing the mechanism underlying the control of SARS-CoV-2-triggered immune-inflammatory responses would help us to understand the pathological process and guide clinical treatment. However, the effect of the NLRP3 inflammasome on regulating SARS-CoV-2-induced inflammatory responses has not been reported. Here, we revealed a distinct mechanism by which SARS-CoV-2 nucleocapsid $(\mathrm{N})$ protein promotes the NLRP3 inflammasome activation to induce hyperinflammation. We demonstrated that $\mathrm{N}$ protein facilitates the maturation of proinflammatory cytokines IL-1 $\beta$ and IL- 6 and induces proinflammatory responses in cultured cells and mice tissues. In team of molecular mechanism, N protein interacts directly with NLRP3 protein, promotes the binding of NLRP3 with ASC, and facilitates the assemble of the inflammasome complex. More importantly, $\mathrm{N}$ protein aggravates lung injury, accelerated death in sepsis and acute inflammation mouse models, and promotes IL-1 $\beta$ and IL- 6 activation in mice. Notably, N-induced lung injury and cytokine production were blocked by Ac-YVAD-cmk, an inhibitor of the NLRP3 inflammasome. Therefore, this study revealed a distinct mechanism by which SARS-CoV-2 N protein promotes the NLRP3 inflammasome activation and induces excessive inflammatory responses.

\section{Introduction}

SARS-CoV-2 infection becomes the most serious public health problem worldwide ${ }^{1}$. The virus was later named "SARS-CoV-2" by the International Committee on Taxonomy of Virus (ICTV) ${ }^{2}$. The World Health Organization (WHO) named this infectious disease as "COVID-19". So far, the number of cases infected by SARS-CoV-2 continues to rise and the WHO has declared that it is a worldwide pandemic (www.who.int/emergencies/diseases/novel-coronavirus-2019/events-as-they-happen). The origin of SARS-CoV-2 remains unclear, and it is speculated that the origin of this virus is more than likely the bat ${ }^{3,4}$. The virus mainly infects the respiratory tract of human beings, causing fever, dry cough, fatigue, shortness of breath, body aches, diarrhea and other symptoms. A small number of critically ill patients may progress to acute respiratory distress syndrome (ARDS), metabolic acidosis, septic shock and clotting dysfunction, or even death in severe cases ${ }^{5-7}$. The infection and transmission of SARS-CoV-2 have caused great harm to human health and social development. Therefore, the pathogenesis of SARSCoV-2 is an urgent scientific problem to be explored.

SARS-CoV-2 infects human lung through the respiratory system and thus cause severe inflammatory responses ${ }^{8,9}$. Significant evidence demonstrated that a dysregulated innate immune response contributes to the clinical presentation of patients with severe COVID-19 ${ }^{10}$. Inflammasome is an important part of the innate immune system. It can recognize cellular stresses and pathogen infections ${ }^{11,12}$. Inflammasomes are named according to different sensing proteins, and there are mainly four types: NLRP1, NLRP3, NLRC4 and $\mathrm{AIM}^{13}{ }^{13}$. Among them, the NLRP3 inflammasome is closely related to RNA virus infection ${ }^{14,15}$, which consists of a sensor protein (NLR family PYRIN domain containing-3, NLRP3), an adaptor protein 
(Apoptosis-associated speck-like protein containing a caspase recruitment domain, ASC), and an effector protein (Caspase-1, Casp-1) ${ }^{16}$. NLRP3 protein contains three domains: Pyrin domain (PYD), Nucleotidebinding domain (NBD), and Leucine-rich repeat domain (LRR) ${ }^{15}$. During activation of the NLRP3 inflammasome, NLRP3 PYD interacts with ASC PYD, promotes ASC oligomer formation, and provides a platform for Casp-1 activation. Active Casp-1 is formed by autocatalytic cleavage, which then catalyzes proteolytic processing of pro-IL-1 $\beta$ into mature IL-1 $\beta^{17}$. Excessive IL-1 $\beta$ stimulates systemic inflammation response by activating different signal pathways such as NF-KB pathway and JNK pathway ${ }^{18,19}$. As a result, it causes the release of large amounts of cytokines including IL-6, TNF- $a$, IFN- $a$, IFN- $\beta$, and TGF- $\beta^{19}$, which may lead to a "cytokine storm" in acute inflammatory diseases. However, the role of the NLRP3 inflammasome in regulating the initiation of the cytokine storm in severe COVID-19 and the effect of SARS-COV-2 infection on triggering the activation of the NLRP3 inflammasome remained unknown.

SARS-CoV-2 belongs to the bate genus Coronavirus in the Coronaviridae family ${ }^{20}$. The spherical viral particle encapsulates its genome, an unsegmented, positive-sense single-stranded RNA with a size of about 30 kilobases $^{20}$. The viral genome is enclosed by nucleocapsid $(\mathrm{N})$ protein, which is buried inside phospholipid bilayers and covered by spike (S) protein. The membrane (M) protein and the envelope (E) protein are located among the $S$ proteins in the virus envelope. In addition, the virus encodes a series of accessory proteins $(3 a, 6,7 a, 8 \text {, and } 10)^{20,21}$. Previous studies have found that severe acute respiratory syndrome coronavirus (SARS-CoV) which also belongs to the coronavirus subfamily with SARS-CoV-2, can activate NLRP3 inflammasome ${ }^{22,23}$. Further studies have revealed that $\mathrm{E}^{22}$ and $3 \mathrm{a}^{23}$ of SARS-CoV activate NLRP3 inflammasome by changing the $\mathrm{K}^{+}$ion permeability of plasma membrane and the production of mitochondrial reactive oxygen species. The specific molecular mechanism by which SARSCoV-2 activates NLRP3 inflammasomes is elusive.

This study uncovered that SARS-CoV-2 N protein induces pro-inflammatory cytokines through promoting the assembly and activation of NLRP3 inflammasome. $\mathrm{N}$ protein aggravated lung injury and accelerated death in acute inflammation mouse models, which was dependent on inflammasome activation. We also demonstrated that SARS-CoV-2 N protein promotes the assembly of the NLRP3 inflammasome through directly interacting with NLRP3 protein. Moreover, SARS-CoV-2 N-induced lung injury and cytokine production were blocked by Ac-YVAD-cmk, an inhibitor of the NLRP3 inflammasome. Thus, this work reveals a distinct molecular mechanism by which SARS-CoV-2 infection causes acute respiratory distress syndrome (ARDS), provides evidence that links the NLRP3 inflammasome and lung injury, and suggests that Ac-YVAD-cmk may act as potential therapeutic agent for the prevention and treatment of COVID-19.

\section{Results}

\section{SARS-CoV-2 $\mathrm{N}$ protein induces proinflammatory responses in cells and mice tissues}

SARS-CoV-2 infection induces hyperinflammatory syndromes characterized by overexpression of proinflammatory factors $5,24,25$. Here, we initially analyzed and compared the expression statuses of 
cytokines and chemokines in mock-infected and SARS-CoV-2-infected macrophages and dendritic cells (DCs) based on the data set GSE155106 from the GEO database. The data showed that expression of proinflammatory cytokines (IL-1 $\beta$, IL-6, TNF- $\alpha$, IL-11, IL-10, and IL-27) and chemokines (CXCL8, CCL2, CXCL10, and IL-7) were significantly induced upon SARS-CoV-2 infection in macrophages (Fig. 1a) and DCs (Fig. 1b). As inflammasome-mediated mature IL-1 $\beta$ induces the release of cytoplasmic proteins and factors and plays an important role in initiating "cytokine storm" ${ }^{19}$, and thus, we evaluated the effect of SARS-CoV-2 proteins on the production of mature IL-1 $\beta$. SARS-CoV-2 genes $(N, M, E, 3 a, 6,7 a, 8$, and 10$)$ encoding for three structural proteins $(\mathrm{N}, \mathrm{M}$, and $\mathrm{E}$ ) and five accessory proteins (ORF3a, ORF6, ORF7a, ORF8, and ORF10) were synthesized based on the sequences of SARS-CoV-2 (GenBank accession number MN908947.3). The synthesized genes were cloned to pcDNA3.1(+) expression vector with HA-tag or Flag-tag. We showed that SARS-CoV-2 N, M, E, ORF3a, ORF6, ORF7a, and ORF8, except ORF10, were expressed in human embryonic kidney 293T (HEK293T) cells transfected with plasmids encoding the proteins (Fig. 1c).

The roles of SARS-CoV- 2 proteins in regulating the secretion of mature IL- $1 \beta$ were assessed in a reconstructed NLRP3 inflammasome system as described previously ${ }^{15}$. HEK293T cells were cotransfected with plasmids encoding the three components (NLRP3, ASC, and pro-Casp-1) of the NLRP3 inflammasome and the substrate pro-IL-1 $\beta$ to generate a NLRP3 inflammasome system. The HEK293TNLRP3 inflammasome system cells were subsequently transfected with plasmids encoding $N, M, E, 3 a, 6$, $7 \mathrm{a}, 8$, and 10 , respectively. ELISA results showed that IL-1 $\beta$ secretion was significantly induced by $N$ protein in this system (Fig. 1d). In addition, human monocytic cell lines (THP-1) were differentiated into macrophages. PMA-differentiated THP-1 macrophages were then transfected with plasmids encoding N, M, E, 3a, 6, 7a, 8, and 10, and stimulated with Nigericin (a specific activator for NLRP3 inflammasome). We noted that the secretion of mature IL-1 $\beta$ was significantly induced by Nigericin, and the Nigericininduced mature IL-1 $\beta$ secretion was further remarkably enhanced by the $N$ protein (Fig. 1e). Collectively, these results demonstrated that SARS-CoV- $2 \mathrm{~N}$ protein plays an important role in the induction of mature IL-1 $\beta$ secretion.

Next, the effect of $\mathrm{N}$ protein on the regulation of proinflammatory cytokines and chemokines was assessed in PMA-differentiated THP-1 macrophages. THP-1 cells were infected with N-Lentivirus (Lentivirus carrying the $\mathrm{N}$ gene) and CT-Lentivirus (as a negative control) to generate two cell lines stable expressing N-Lentivirus and CT-Lentivirus, respectively (Fig. 1f). The stable cells were subsequently differentiated into macrophages. qRT-PCR analyses showed that the expression of IL-1 $\beta$, IL-6, TNF-a, CXCL10, IL-11, IL-13, CCL2, and CXCL8 mRNAs was notably elevated by Lentivirus-N, whereas the expression of IL-18, IL-10, and VEGFA mRNAs was not affected by Lentivirus-N (Fig. 1g).

Moreover, the role of $\mathrm{N}$ protein in the regulation of proinflammatory cytokines and chemokines was evaluated in mice. C57BL/ 6 mice were tail vein injection with adenovirus associated virus (AAV)-LungEGFP (control), AAV-Lung-N, and AAV-Lung-N plus Ac-YVAD-cmk (a selective irreversible inhibitor of Caspase- 1 that blocks IL-1 $\beta$ maturation), respectively. We noted that $N$ protein was expressed in the lung of mice injected with AAV-Lung-N, but not detected in the liver or spleen of mice injected with AAV-Lung-N 
(Fig. 1h). qRT-PCR analyses showed that IL-1 $\beta$, IL-6, TNF-a, CXLC10, CCL2, IL-11, IL-7, and CXCL8 mRNAs were notably induced in the lung of mice injected with AAV-Lung-N, but relatively unaffected in the lung of mice injected with AAV-Lung-CT (Fig. 1i). Interestingly, N-induced expression of IL-1ß, IL-6, TNF-a, CXLC10, CCL2, IL-11, IL-7, and CXCL8 were significantly suppressed by Ac-YVAD-cmk (Fig. 1i). Taken together, these results demonstrated that SARS-CoV-2 N protein plays a critical role in the induction of proinflammatory cytokines, and suggested that $\mathrm{N}$ protein may involve in regulating the activation of the NLRP3 inflammasome.

\section{IL-1 $\beta$ maturation and IL- 6 production are induced by SARS-CoV-2 $\mathrm{N}$ protein}

Given the dominant effect of the inhibitor on the expression of the pro-inflammatory factors, we further determined the role of SARS-CoV-2 N protein in IL-1 $\beta$ maturation. HEK293T-NLRP3 inflammasome system cells were transfected with plasmid encoding SARS-CoV-2 N protein at different concentrations. The results showed that IL-1 $\beta$ secretion (Fig. 2a) and IL-1 $\beta$ (p17) cleavage as well as Casp-1 (p20) maturation (Fig. $2 b$ ) were induced by $\mathrm{N}$ protein in dose-dependent fashions.

Next, PMA-differentiated THP-1 macrophages were transfected with plasmids encoding SARS-CoV-2 N at different concentrations and treated with Nigericin. We noted that IL-1 $\beta$ secretion was induced by Nigericin and the Nigericin-induced IL-1 $\beta$ secretion was further promoted by $N$ protein in a dosedependent manner (Fig. 2c). Similarly, IL-1 $\beta$ (p17) cleavage and Casp-1 (p20) maturation were induced by Nigericin and Nigericin-induced IL-1 $\beta$ (p17) cleavage and Casp-1 (p20) maturation were further facilitated by $\mathrm{N}$ protein in concentration-dependent fashions (Fig. 2d). However, we found that the level of mature IL18 was relatively unaffected by $\mathrm{N}$ protein (Fig. 2e), although its maturation and production relied on the same cleavage mechanism as IL-1 $\beta$.

In addition, THP-1 cells stably infected with CT-Lentivirus and N-Lentivirus were differentiated into macrophages, which were then treated with LPS plus ATP or LPS plus Nigericin. The results indicated that IL-1 $\beta$ secretion was induced by LPS plus ATP or LPS plus Nigericin, and such inductions were further enhanced significantly by $N$ protein (Fig. 2f). Consistently, IL-1 $\beta$ (p17) cleavage was also induced by LPS plus ATP or LPS plus Nigericin, and such inductions were further enhanced by N protein (Fig. 2g). We noted that the level of mature IL-18 was induced by LPS plus ATP or LPS plus Nigericin, but such inductions were relatively unaffected by $\mathrm{N}$ protein (Fig. $2 \mathrm{~h}$ ). Notably, the production of widely described proinflammatory cytokine IL- 6 was induced by LPS plus ATP or LPS plus Nigericin, and such induction was also further enhanced by N protein (Fig. 2i). Moreover, IL-6 production was confirmed to be induced by $\mathrm{N}$ protein in a dose-dependent manner (Fig. 2j).

Finally, granulocyte macrophage-colony stimulating factor (GM-CSF) differentiated mice bone marrowderived monocytes (BMDMs) were infected with CT-Lentivirus or N-Lentivirus and stimulated with LPS, LPS plus ATP, or LPS plus Nigericin. In the treated mouse BMDMs, IL-1 $\beta$ secretion was activated by LPS plus ATP or LPS plus Nigericin, and such activations were further facilitated notably by N protein (Fig. 
2k). Similarly, IL-6 production was also induced by LPS plus ATP or LPS plus Nigericin, and such inductions were further promoted by $\mathrm{N}$ protein in treated mice BMDMs (Fig. 2l). Therefore, our results demonstrated that SARS-CoV- $2 \mathrm{~N}$ protein induces IL-1 $\beta$ maturation and IL- 6 production and suggested that $\mathrm{N}$ protein may play an important role in the activating the NLRP3 inflammasome.

\section{SARS-CoV-2 N protein interacts with NLRP3 protein}

The role of SARS-CoV-2 N protein in the regulation of NLRP3 inflammasome was then investigated. Initially, the interaction of N protein with the NLRP3 inflammasome components, NLRP3, ASC, and Caspase-1, was explored. Co-immunoprecipitation (Co-IP) assays showed that $\mathrm{N}$ protein only interacted with NLRP3 protein and failed to interact with ASC protein or Casp-1 protein in HEK293T and A549 cells (Fig. 3a, b). Reciprocal Co-IP assays further conformed that NLRP3 interacted with N in HEK293T and A549 cells (Fig. 3c, d). Importantly, we demonstrated that purified His-N protein could directly bind to NLRP3 protein (Fig. 3e). Moreover, confocal microscope analyses showed that in HEK293T and A549 cells, N protein and NLRP3 protein were co-localized in the cytoplasm (Fig. $3 \mathrm{f}, \mathrm{g}$ ), and N protein failed to interact with ASC (Fig. 3h, i). Taken together, these results demonstrated that $\mathrm{N}$ protein interacts with NLRP3 protein to regulate the NLRP3 inflammasome.

\section{Sequence 260 aa to 340 aa of N protein involves in the NLRP3 inflammasome activation}

The sequences of SARS-CoV-2 N protein involved in the interaction with NLRP3 protein were determined by evaluating progressive truncated mutants of N protein, N1-N8 (Fig. 4a). Co-IP results showed that NLRP3 interacted with N1(1-340), N5(90-420), N6(180-420), and N7(260-420), but failed to interact with N2(1-260), N3(1-180), N4(1-90), and N8(340-420) in HEK293T cells (Fig. 4b, c) and A549 cells (Fig. 4d), suggesting that the domain containing 260aa-340aa of $\mathrm{N}$ protein is involved in the interaction with NLRP3.

Next, the effect of N protein progressive truncations (N1-N8) on the activation of the NLRP3 inflammasome was evaluated. The HEK293T-NLRP3 inflammasome system cells were transfected with plasmids encoding $N$ protein or its truncated mutants $N 1$ to $N 8$, respectively. ELISA assays showed that IL-1 $\beta$ secretion, IL-1 $\beta$ p17 cleavage, and Casp-1 p20 maturation in the cell supernatants were significantly induced by the N1, N5, N6, and N7, but not affected by N2, N3, N4, and N8 (Fig. 4e), indicating that the domain containing 260aa-340aa of $\mathrm{N}$ protein is involved in the activation of the NLRP3 inflammasome. Taken together, we demonstrated that the sequence 260aa-340aa of SARS-CoV-2 N interacts with NLRP3 to activate the NLRP3 inflammasome. 
As SARS-CoV-2 N interacts with NLRP3, we would like to know the role of $\mathrm{N}$ in regulating the components of the NLRP3 inflammasome. Initially, the effect of N protein on the expression of NLRP3, Casp-1, and ASC was examined. The results showed that the protein levels of NLRP3, Caspase-1, and ASC were not influenced by $\mathrm{N}$ protein in HEK293T cells (Fig. 5a). However, $\mathrm{N}$ and ASC could interact with each other in the presence of NLRP3 in HEK293T cells (Fig. 5b, c) and A549 cells (Fig. 5d, e), suggesting that N, NLRP3, and ASC three proteins together might form a complex N-NLRP3-ASC. Interestingly, the interaction of NLRP3 and ASC was enhanced by N protein in dose-dependent manners in HEK293T cells (Fig. 5f) and A549 cells (Fig. $5 \mathrm{~g}$ ). Co-IP results also demonstrated that N protein interacted with endogenous ASC in the presence of NLRP3 and the interaction was promoted by stimulating with Nigericin in PMAdifferentiated THP-1-N cells (Fig. 5h). Taken together, these results suggested that SARS-CoV-2 N promotes the interaction of NLRP3 with ASC.

\section{The assemble of the NLRP3 inflammasome is facilitated by SARS-CoV-2 N protein}

The role of SARS-CoV-2 N protein in regulating the assemble of the NLRP3 inflammasome was then explored. Localization of NLRP3 as speck structure in the cytoplasm is an indicator of inflammasome complex formation ${ }^{30}$. In HEK293T cells (Fig. 6a, top) and A549 cells (Fig. 6a, bottom), NLRP3 alone was diffusely distributed in the cytoplasm, whereas in the presence of SARS-CoV-2 N protein, NLRP3 colocalized with $\mathrm{N}$ and formed specks (Fig. 6a). We noted that N2 (1aa-260aa) (Fig. 6b) and N8 (340aa420aa) (Fig. 6c) were distributed in both the nucleus and cytoplasm and failed to co-localize with NLRP3, and NLRP3 failed to form specks in the cytoplasm of HEK293T cells (Fig. 6b, c, top) and A549 cells (Fig. $6 \mathrm{~b}, \mathrm{c}$, bottom). Confocal microscope showed that in PMA-differentiated THP-1 macrophages, N protein alone was diffusely distributed in the cytoplasm (Fig. 6d); endogenous NLRP3 protein alone also diffusely located in the cytoplasm (Fig. 6e, top); however, in the presence of $\mathrm{N}$ protein, endogenous NLRP3 protein aggregated and formed specks in the cytoplasm (Fig. 6e, bottom). Collectively, these data suggested that SARS-CoV-2 N protein may promote the formation of the NLRP3 inflammasome complex.

In the process of inflammasome assembly, ASC protein is aggregated to form oligomers, which is required for Casp-1 activation ${ }^{31}$. Notably, in PMA-differentiated THP-1 macrophages (Fig. 6f) and GMCSF differentiated BMDMs (Fig. 6g), oligomerization of endogenous ASC protein was stimulated by Nigericin, and Nigericin-induced ASC oligomerization was further enhanced in the presence of $\mathrm{N}$ protein (Fig. 6f, g). In addition, HEK293T-NLRP3 inflammasome system cells were transfected with plasmids encoding SARS-CoV-2-N protein and its truncated mutants, respectively. Notably, ASC oligomerization was activated by N1, N5, N6, and N7 proteins, but not influenced by N2, N3, N4, and N8 proteins (Fig. 6h), demonstrating that the sequence $260 \mathrm{aa}-340 \mathrm{aa}$ of $\mathrm{N}$ protein interacts with NLRP3 to promote ASC oligomerization.

Moreover, we explored the effect of N protein on the assembly of the NLRP3 inflammasome complex. HEK293T cells (Fig. 6i) and A549 cells (Fig. 6j) were co-transfected with plasmids as indicated. In the 
presence of GFP and NLRP3, GFP was distributed in both cytoplasm and nucleus, NLRP3 was diffusely distributed in the cytoplasm (Fig. $6 \mathrm{i} a-e$ and Fig. $6 \mathrm{j} a-e$ ). In the presence of N and NLRP3, NLRP3 was colocalized with $\mathrm{N}$ and formed speck structures (Fig. $6 \mathrm{i} f-j$ and Fig. $6 \mathrm{j} f-j$ ). In the presence of GFP and ASC, GFP was distributed in both cytoplasm and nucleus, ASC was distributed in nucleus and cytoplasm and formed small ring structures (Fig. $6 \mathrm{i} k-o$ and Fig. $6 \mathrm{j} k-o$ ). When $\mathrm{N}$ and ASC presented together, $\mathrm{N}$ and ASC were not colocalized (Fig. 6i $p-t$ and Fig. $6 \mathrm{j} p-t$ ). Notably, in the presence of GFP, ASC, and NLRP3, NLRP3 and ASC were co-localized in the cytoplasm to form "ring-like" structures (Fig. 6i $u-y$ and Fig. 6j $u-y$ ). Importantly, when N, ASC, and NLRP3 expressed together, the three protein were obviously colocalized to form "sphere-like" structures (Fig. 6i z-ad and Fig. 6j z-ad). Taken together, these data demonstrated that SARS-CoV-2 N protein promotes the assemble of the NLRP3 inflammasome complex.

\section{SARS-CoV-2 $\mathrm{N}$ protein induces mice lung injury via activating the NLRP3 inflammasome}

The biological role of SARS-CoV-2 N protein in activating the NLRP3 inflammasome was then assessed. As the main clinical symptom of COVID-19 is acute lung injury ${ }^{5}$, and the "cytokine storm" is considered to be an important cause of acute lung injury ${ }^{25}$. Therefore, we explored the effect of $\mathrm{N}$ protein on lung injury using an AAV-lung-N C57BL/ 6 mouse model. C57BL/ 6 mice were subjected to tail vein injection with AAVLung-EGFP or AAV-Lung-N. The results indicated that the protein levels of IL-1 $\beta$ and IL- 6 in the sera were significantly higher in AAV-N-infected mice than that in AAV-CT-infected mice (Fig. 7a, b). Additionally, C57BL/ 6 mice injected with AAV-Lung-EGFP or AAV-Lung-N were subjected to intraperitoneal injection with or without Ac-YVAD-cmk. We noted that the protein levels of IL-1 $\beta$ and IL- 6 were much higher in the sera of AAV-N-infected mice as compared to AAV-CT-infected mice, however, AAV-N-mediated inductions of IL-1 $\beta$ and IL-6 were repressed by Ac-YVAD-cmk (Fig. 7c, d). Notably, immunohistochemical fluorescence analyses showed that IL-1 $\beta$ and IL- 6 proteins were highly expressed in the lungs of mice carrying AAV-Lung-N, whereas such activations were attenuated by Ac-YVAD-cmk (Fig. 7e, f). Interestingly, hematoxylin \& eosin staining analyses indicated that inflammatory lesions and tissue injuries were obvious in the lungs of mice carrying AAV-Lung-N, but such pathological changes were repressed by the administration of Ac-YVAD-cmk (Fig. 7g). Collectively, these results suggested that $\mathrm{N}$ protein induces a systemic inflammation and lung injury in mice via activating the NLRP3 inflammasome.

C57BL/6 mice were tail vein injected with AAV-Lung-EGFP or AAV-Lung-N, treated with PBS or LPS, and intraperitoneally injected with or without Ac-YVAD-cmk, as indicated. Interestingly, the survival rates were reduced in mice treated with LPS; relatively unchanged between mice treated with LPS plus injected with AAV-Lung-EGFP and mice treated with LPS; further downregulated significantly in mice treated with LPS plus injected with AAV-Lung-N; and recovered in mice treated with LPS plus injected with AAV-Lung-N and treated with Ac-YVAD-cmk (Fig. 7h). N protein specifically expressing in lung significantly shortened survival time of mice (Fig. 7h). Taken together, we reveal a pathological mechanism of COVID-19, in which SARS-CoV-2 $\mathrm{N}$ protein promotes inflammation and lung injury via promoting the activation of the NLRP3 inflammasome (Fig. 8). 


\section{Discussion}

SARS-CoV-2 infection could cause acute lung injury, and one of the important reasons is dysregulation of the immune system in the lung $\mathrm{g}^{8,9}$ that results in the release of a large number of inflammatory factors and forms "cytokine storm"10. In this study, we found that SARS-CoV-2 infection of macrophages and dendritic cells would promote the expression of abundant cytokines and chemokines by analyzing the GEO database (GSE155106). Next, through screening, we found that SARS-CoV-2 N protein promoted the expression of inflammatory factors by activating NLRP3 inflammasome, resulting in mouse lung injury and exacerbating the death of mice in the sepsis model. Further studies indicated that $\mathrm{N}$ protein directly interacted with NLRP3 to promote the assembly of NLRP3 inflammasome and thereby activated NLRP3 inflammasome. Above all, our results demonstrated a novel mechanism by which SARS-CoV- $2 \mathrm{~N}$ protein induced lung injury through NLRP3 inflammasome.

As an important part of the innate immune system, NLRP3 inflammasome plays a crucial role in the recognition of cell damage and pathogenic microbial infection ${ }^{11-14}$. Our previous studies found that $\mathrm{M}$ protein of Dengue virus caused tissue damage and vascular leakage in mice by activating NLRP3 inflammasome ${ }^{15}$, while NS5 protein of Zika virus promoted virus entry into the brain, which aggravated the death of mice by activating NLRP3 inflammasome ${ }^{27}$. Whether NLRP3 inflammasome plays a vital role in COVID-19? In this work, we found that SARS-CoV-2 N protein could promote the expression of inflammatory factors. However, after adding Ac-YVAD-cmk, a specific inhibitor of NLRP3 inflammasome ${ }^{26}$, the levels of $\mathrm{N}$ protein induced inflammatory factors were restored. $\mathrm{N}$ protein, as the main structural protein of SARS-CoV-2, is involved in virus replication, assembly and immune regulation ${ }^{32,33}$. As the most stably expressed structural protein, it is the gold standard in nucleic acid test of SARS-CoV-2. Recent research has also found that N protein combats host RNAi-mediated antiviral response through its double-stranded RNA-binding activity ${ }^{34}$ and $\mathrm{N}$ protein can induce both humoral and cellular immune response after infection ${ }^{35}$. Our results demonstrated that SARS-CoV-2 $\mathrm{N}$ protein could also induce innate immune response through activating NLRP3 inflammasome, and increased the risk of activating the acute inflammatory response.

As important inflammatory factors in the innate immune system, IL-1 $\beta$ and IL-6 play important roles in the host defense against the virus ${ }^{36}$. Our previous studies have shown that Dengue virus promotes vascular leakage in mice by inducing IL- $1 \beta$ production ${ }^{37}$. Moreover, IL- $1 \beta$ is a highly potent proinflammatory mediator that induces vasodilation and attracts granulocytes to the inflamed tissues ${ }^{38}$. Similar to the function of IL-1 $\beta$, IL- 6 also plays amplifying the innate immune response by recruiting additional immune mediators ${ }^{39}$. Clinical research found that the expression of IL-1 $\beta$ and IL- 6 in serum and alveolar lavage fluid are significantly increased in patients infected with SARS-CoV- ${ }^{7}$. Our results also demonstrated that the levels of IL- $1 \beta$ and IL- 6 in sera and lung were increased by the lung-specific expression of $N$ protein, but the expressions of IL-1 $\beta$ and IL- 6 were significantly decreased by the administration of Ac-YVAD-cmk. More interestingly, in the sepsis mouse mode ${ }^{28}, \mathrm{~N}$ protein significantly increased the time of mouse death, while the addition of Ac-YVAD-cmk, it is not only delayed the time of 
death but also improved the survival rate of the mice. This suggests that SARS-CoV- $2 \mathrm{~N}$ protein may cause lung injury through inducing the production of proinflammatory factors, like IL-1 $\beta$ and IL-6.

NLRP3 inflammasome is composed of sensor protein (NLRP3), adaptor protein (ASC) and effector protein (Caspase- 1$)^{16}$. During the activation of NLRP3 inflammasome, NLRP3 deubiquitination ${ }^{40}$ and self-aggregation ${ }^{30}$ firstly occurs, followed by ASC recruitment and oligomerization ${ }^{31}$, and then procaspase- 1 is cut into active caspase-1 (p20) which can cleave pro-IL-1 $\beta$ and pro-IL-18 to produce mature $\mathrm{IL}-1 \beta$ ( $\mathrm{p} 17)$ and IL-18 respectively ${ }^{17}$. Our results proved that SARS-CoV-2 N protein could directly interact with NLRP3 to promote the aggregation of NLRP3 protein, and further studies indicated that N protein could accelerated the interaction between NLRP3 and ASC, thus facilitated the oligomerization of ASC. Immunofluorescence experiments proved that the N-NLRP3-ASC would form a complex, leading to the activation of NLRP3 inflammasome. Even more interestingly, CO-IP experiment indicated that the CTD domain of $\mathrm{N}$ protein (260aa-340aa) ${ }^{33}$ mediates the interaction with NLRP3. Moreover, missing this domain, the levels of p17, p20 and ASC oligomerization was significantly reduced. This further indicates that the interaction between N and NLRP3 protein is essential for activating the NLRP3 inflammasome. It is worth noting that our results found that N protein has no effect on the expression of IL-18, which also as an effector protein downstream of the NLRP3 inflammasome ${ }^{16}$, seeming a little contradiction. We speculated that maybe $\mathrm{N}$ protein had no effect on the mRNA level of IL-18, leading to an extremely low level of protein expression, so the effect of $\mathrm{N}$ protein on IL-18 was not detected in our experiment.

In conclusion, our study demonstrated that SARS-CoV-2 nucleocapsid protein $(\mathrm{N})$ could directly interact with NLRP3 to promote the assembly and activation of NLRP3 inflammasome, thus leading to the production of a large number of inflammatory factors and the occurrence of lung injury in mice. Our data indicated that inhibition of NLRP3 inflammasome could reduce "cytokine storm" and lung injury caused by SARS-CoV-2 infection, suggesting that NLRP3 inflammasome might be a potential target for COVID-19 therapy.

\section{Materials And Methods}

\section{Animal study}

Wild-type C57BL/6 mice were purchased from Guangdong Medical Laboratory Animal Center, Guangzhou, China. Mice were bred and maintained under specific pathogen-free conditions at Jinan University. 6-week-old mice were tail vein injected with $300 \mu$ l of AAV-Lung-EGFP-N $\left(5 \times 10^{11} \mathrm{vg}\right)$ or AAVLung-EGFP (Purchased from OBiO Technology, Shanghai, China). Sera were collected at one week and three weeks for all groups from retro-orbital. After four weeks, mice were treated with LPS (30 mg / $\mathrm{kg})$ by intraperitoneal injection ${ }^{28}$. Mice were sacrificed and tissues were collected for histoimmunofluorescence or histopathology analysis.

Mouse bone marrow-derived macrophages (BMDM) were isolated from 6-week old male C57BL/ 6 mice. Cells were cultured in RPMI 1640 medium with 10\% FBS and 10\% GM-CSF conditioned medium from 


\section{Ethics statement}

All animal studies were performed in accordance with the principles described by the Animal Welfare Act and the National Institutes of Health Guidelines for the care and use of laboratory animals in biomedical research. All procedures involving mice and experimental protocols were approved by Institute of laboratory animal science, Jinan University. The animal ethic committee date and number is 2020082809. All the mice that need to be sacrificed were used the method of euthanasia.

\section{Cell lines and cultures}

Embryonic kidney cell lines (HEK-293T), human pulmonary epithelial cell (A549) and Human monocytic cell lines (THP-1) were purchased from American Type Culture Collection (ATCC). HEK293T and A549 cells were grown in DMEM medium and THP-1 cells were grown in RPMI 1640 medium. All the medium was supplemented with $10 \%$ fetal calf serum, $100 \mathrm{U} / \mathrm{ml}$ penicillin, and $100 \mu \mathrm{g} / \mathrm{ml}$ streptomycin, and maintained at $37^{\circ} \mathrm{C}$ in a $5 \% \mathrm{CO}_{2}$ incubator. THP-1 cells were differentiated into macrophages by stimulating with Phorbol-12-myristate-13-acetate (PMA) for $12 \mathrm{~h}$. Then the cells were cultured in fresh medium for $24 \mathrm{~h}$ and stimulated with Nigericin, LPS, or ATP. Supernatants were collected for measurement of IL-6, IL-18, IL-1 $\beta$ (p17). Cells were harvested for qRT-PCR and immunoblot analysis.

\section{Reagents and antibodies}

Human IL-1 $\beta$ ELISA kit was purchased from BD Biosciences. Human IL-6, human IL-18, mouse IL-6, mouse IL-1 $\beta$ ELISA kit weas purchased from MULTI SCIENCES. PMA, Nigericin, LPS, ATP and dansylsarcosine piperidinium salt (DSS) were purchased from Sigma-Aldrich. Lipofectamine 2000 reagent was purchased from Invitrogen. Trizol reagent was purchased from Ambion.

Anti-NLRP3 (D4d8T), anti-Caspase-1 (D7F10) and anti-IL-13 (D3U3E) antibodies were purchased from Cell Signaling Technology. Anti-NLRP3 (ALX-804-818) were purchased from Enzo Life Science. AntiSARS-CoV-2-N (A20021) and anti- $\beta$-actin (AC026) antibody was purchased from ABclonal. Anti-Flag (F3165), anti-HA (H6908) and anti-GAPDH (G8759) were purchased from Sigma. Anti-ASC (sc-271054) was purchased from Santa Cruz Biotechnology. Rabbit IgG and Mouse IgG were purchased from Invitrogen. Anti-mouse/rabbit IgG Dylight 649, anti-mouse/rabbit IgG Dylight cy3, and anti-mouse/rabbit IgG FITC were purchased from Abbkine. 


\section{RNA extract and qRT-PCR}

Total RNAs were extracted by using Trizol reagent (Invitrogen, CA) according to the manufacturer's instructions. Real-time quantitative reverse transcriptase-PCR (qRT-PCR) was performed using the Roche LC480 and SYBR RT-PCR Kits (Invitrogen). The Real-time PCR primers were designed by Primer-blast, NCBI (www.ncbi.nlm.nih.gov) and their sequences are listed in Table 1.

\section{Plasmid construction}

The 8 genes (N, M, E, 3a, 6, 7a, 8, and 10) of SARS-CoV-2 (GenBank accession number MN908947.3) were synthesized by GenScript, Nanjing, China and cloned to vector pcDNA3.1(+) expression vector with HAtag or Flag-tag. For the truncated forms of SARS-CoV-2-N, the PCR productions were inserted into the Xbal and BamHI sites of plasmid pcDNA3.1(+)-3xflag. The sequences of primers were shown in Table 2. Plasmids pcDNA3.1(+)-3×flag-NLRP3/Caspase-1/ ASC/IL-1 $\beta$, and pCAGGS-HA-NLRP3/ASC/ Caspase-1 were constructed previously by our laboratory.

\section{Lentivirus -mediated gene expression and Cell transfection}

HEK293T cells were seeded in $10 \mathrm{~cm}$ dishes and transfected with plenti-3×flag-SARS-CoV-2-N or negative control empty vector along with the packing plasmids psPAX2 and pMD2G using Lipo2000 transfection reagent. The medium was changed $12 \mathrm{~h}$ after transfection. $36 \mathrm{~h}$ and $60 \mathrm{~h}$ post transfection, cell supernatants containing lentivirus were collected and filtrated with $0.45 \mu \mathrm{m}$ filter. PMA-differentiated THP-1 macrophages and GM-CSF-differentiated BMDMs were introducted with lentivirus for $24 \mathrm{~h}$ adding ploybrene (Sigma, TR-1003). 48h after introduction, the cells were selected with puromycin (Sigma, P8833) for 4-7 days. HEK293T cells were transfected with indicated plasmids using PEI (Sigma, T0956) and THP-1 or A549 cells were transfected with indicated plasmids using Lipo2000 transfection reagent. The system of the NLRP3 inflammasome in HEK293T cells in vitro, please refer to previous papers published by our lab ${ }^{15}$.

\section{Enzyme-linked immunosorbent assay}

The concentration of culture cell supernatants and mice serum of IL-6, IL-1 $\beta$, and IL-18 were measured by related ELISA Kit according to manufacturer's instructions.

\section{Western-blot}


PMA-differentiated THP-1 macrophages and GM-CSF-differentiated BMDM were washed twice with PBS and dissolved in lysis buffer (50 mM Tris- $\mathrm{HCl}, \mathrm{pH} 7.4,150 \mathrm{mM} \mathrm{NaCl}, 0.1 \%$ Nonidetp40, 5 mM EDTA, and $10 \%$ glycerol). A549 cells and HEK-293T cells were prepared in lysis buffer (50 mM Tris- $\mathrm{HCl}, \mathrm{pH7.4,300}$ $\mathrm{mM} \mathrm{NaCl}, 1 \%$ Triton X-100, 5 mM EDTA, and 10\% glycerol). 10\% protease inhibitor (Roche) was added to lysis buffer before using. Protein concentration was measured by Bradford assay (Bio-Rad, Richmond, CA). Cell lysates $(50 \mu \mathrm{g})$ were electrophoresed on 8-12\% SDS PAGE and transferred to nitrocellulose membranes (Amersham, Piscataway, NJ). Nonspecific bands of NC membranes were blocked by $5 \%$ skim milk for $2 \mathrm{~h}$. NC membranes were washed three times with PBS with $0.1 \%$ Tween (PBST) and incubated with indicated antibodies. Protein bands were visualized using a Bio-Rad Image Analyzer (Serial N0.733BR3722).

\section{Co-immunoprecipitation assays}

A549, HEK293T, PMA-differentiated THP-1 cells, and THP-1-SARS-CoV-2-N stable cells grown to 70-80\% confluence in $6-\mathrm{cm} / 10-\mathrm{cm}$ dishes were co-transfected with indicated plasmids for $24-48 \mathrm{~h}$. Transfected HEK293T cells or A549 cells were lysed in lysis buffer (50 mM Tris-HCl, pH7.4, 300 mM NaCl, 1\% Triton X100, 5 mM EDTA, and 10\% glycerol) and transfected THP-1 cells were dissolved in lysis buffer (50 mM Tris- $\mathrm{HCl}, \mathrm{pH} 7.4,150 \mathrm{mM} \mathrm{NaCl}, 0.1 \%$ Nonidetp40, 5 mM EDTA, and 10\% glycerol). The lysates were rotated at $4^{\circ} \mathrm{C}$ for $30 \mathrm{~min}$ and centrifuged at $12000 \mathrm{rpm}$ for $10 \mathrm{~min}$ to remove debris. A aliquot of supernatants were used as Input, and the rest supernatants were incubated with indicated antibodies overnight at $4^{\circ} \mathrm{C}$, and mixed with Protein G sepharose beads (GE Healthcare, Milwaukee, WI, USA) for $2 \mathrm{~h}$ at $4^{\circ} \mathrm{C}$. Immunoprecipitates were washed 4-6 times with respective lysis buffer, boiled in protein loading buffer, and analyzed by Western blotting.

\section{His-pull-down assays}

To construct pET-28a-His-N, N gene was sub-cloned into pET-28a-His at EcoRI and Xhol sites. Plasmid pET-28a-His-N was transfected into Escherichia coli strain BL21. After growing in Kanamycin-resistant LB medium at $37^{\circ} \mathrm{C}$ until $\mathrm{OD}_{600}$ reached $0.6-0.8$, IPTG was added to a concentration of $0.2 \mathrm{mM}$, and medium was transferred to $16^{\circ} \mathrm{C}$ for $12-16 \mathrm{~h}$. Cells were harvested and sonicated in lysis buffer (50 mM $\mathrm{NaH}_{2} \mathrm{PO}_{4}, 100 \mathrm{mM}$ PMSF, 300mM NaCl, 10mM imidazole, pH8.0). Lysates were centrifuged at $12000 \mathrm{rpm}$ for $15 \mathrm{~min}$ to move debris. Supernatants were loaded into Ni-NTA Agarose columns (QIAGEN), shaken at $4^{\circ} \mathrm{C}$ for $2 \mathrm{~h}$, and slowly flowed from columns and washed twice with wash buffer $\left(50 \mathrm{mM} \mathrm{NaH}_{2} \mathrm{PO}_{4}, 100\right.$ mM PMSF, 300 mM NaCl, 20 mM imidazole, pH8.0). Recombinant His-N protein was eluted using elution buffer (50 mM NaH${ }_{2} \mathrm{PO}_{4}, 100$ mM PMSF, 300 mM NaCl, 250 mM imidazole, pH8.0). Recombinant His-N containing reduced imidazole was replaced into PBS using Millipore ultrafiltration tube. Ni-NTA Agarose were incubated with purified His-N at $4^{\circ} \mathrm{C}$ for $2 \mathrm{~h}$, and incubated with cell lysates from HEK293T cells 
transfected with pcDNA3.1(+)-3xflag-NLRP3 for $16 \mathrm{~h}$ at $4^{\circ} \mathrm{C}$. Precipitates were washed 4 times with PBS, boiled in protein loading buffer, and separated by SDS-PAGE.

\section{Confocal microscopy}

HEK293T and A549 cells grown on sterile cover slips were transfected with indicated plasmids at $40 \%$ confluence for $24 \mathrm{~h}$. PMA-differentiated THP-1-CT or THP-1-N stable cells grown on sterile cover slips for $24 \mathrm{~h}$. Cells were fixed with $4 \%$ paraformaldehyde for $30 \mathrm{~min}$, washed 3 times with ice-cold PBS containing $0.1 \%$ BSA, and permeabilized with PBS containing $0.2 \%$ TritonX-100 for $5 \mathrm{~min}$. Washed three times with PBS, and finally blocked with PBS containing $5 \%$ BSA for $1 \mathrm{~h}$. Cells were incubated overnight with anti-HA antibody, anti-Flag antibody and anti-NLRP3 antibody (1:200 in PBS) followed by staining with Cy3conjugated donkey anti-rabbit IgG, FITC-conjugated donkey anti-mouse IgG and Daylight 649-conjugated donkey anti-rabbit IgG secondary antibody (Abbkine) (1:100 in wash buffer). Nuclei were stained with DAPI for $5 \mathrm{~min}$, and the cells were washed 3 times. Cells were viewed under confocal fluorescence microscope (Leica, TCS, SP8).

\section{ASC oligomerization analysis}

HEK293T cells, PMA-differentiated THP-1 cells, and GM-CSF-differentiated BMDM were lysed in lysis buffer, gently shaken at $4{ }^{\circ} \mathrm{C}$ for $30 \mathrm{~min}$, and centrifuged at $6000 \mathrm{rpm}$ at $4^{\circ} \mathrm{C}$ for $10 \mathrm{~min}$. Pellets were washed 3 times with PBS and re-suspended in $200 \mu$ PBS. 2 mM DSS (Sigma) was added to resuspended pellets, which were cross-linked at $37^{\circ} \mathrm{C}$ for $30 \mathrm{~min}$. The samples were centrifuged at 6000 rpm for $10 \mathrm{~min}$, cross-linked pellets were re-suspended in $50 \mu \mathrm{l} 2 \times$ SDS loading buffer, boiled for $10 \mathrm{~min}$, and analyzed by Western blotting.

\section{Statistical analyses}

All experiments were repeated at least three times with similar results. All results were expressed as the mean \pm the standard Error of mean (SEM). Statistical analysis was carried out using the t-test for two groups and one-way ANOVA for multiple groups (GraphPad Prism7). The date was considered statistically significant when $\left.\left.\mathrm{P} \leq 0.05(*), \mathrm{P} \leq 0.01{ }^{(\star *}\right), \mathrm{P} \leq 0.001{ }^{(* \star}\right)$.

\section{Declarations}

Acknowledgements 
This work was supported by National Natural Science Foundation of China (81730061), Guangdong Province "Pearl River Talent Plan" Innovation and Entrepreneurship Team Project (2017ZT07Y580), and China Postdoctoral Science Foundation (2020T130046ZX).

\section{Author contributions}

P.P., M.S., Z.Y., Y.L., and J.W. contributed to the design of experiments. P.P., M.S., Z.Y., W.G. K.C., M.T., F.X., G.L., Z.W., J.W., Y.J., W.W., P.W., J.Z., W.C., Z.L., X.C., Z.L., Q.Z., M.X., and Y.L. contributed to the conduction of experiments. P.P., M.S., Z.Y., W.G. K.C., M.T., F.X., G.L., Z.W., J.W., Y.J., W.W., P.W., J.Z., W.C., Z.L., X.C., Z.L., Q.Z., M.X., Y.L., and J.W. contributed to the reagents. P.P., M.S., Z.Y., Y.L., and J.W. contributed to the writing the paper. P.P., Y.L., and J.W. contributed to the editing the paper.

Competing financial interests: The authors have no conflicts of interest to disclose.

\section{References}

1. Li, Q. et al. Early Transmission Dynamics in Wuhan, China, of Novel Coronavirus-Infected Pneumonia. New Engl. J. Med. 382, 1199-1207 (2020).

2. Gorbalenya, A. E. et al. The species Severe acute respiratory syndrome-related coronavirus: classifying 2019-nCoV and naming it SARS-CoV-2. Nat Microbiol. 5, 536-544 (2020).

3. Wrobel, A. G. et al. SARS-CoV-2 and bat RaTG13 spike glycoprotein structures inform on virus evolution and furin-cleavage effects. Nat. Struct. Mol. Biol. 27, 763-767 (2020).

4. Latinne, A. et al. Origin and cross-species transmission of bat coronaviruses in China. Nat. Commun. 11, (2020).

5. Huang, C. et al. Clinical features of patients infected with 2019 novel coronavirus in Wuhan, China. Lancet. 395, 497-506 (2020).

6. Chu, D. K. et al. Physical distancing, face masks, and eye protection to prevent person-to-person transmission of SARS-CoV-2 and COVID-19: a systematic review and meta-analysis. Lancet. 395, 1973-1987 (2020).

7. Huang, C. et al. Clinical features of patients infected with 2019 novel coronavirus in Wuhan, China. Lancet. 395, 497-506 (2020).

8. Abdin, S. M., Elgendy, S. M., Alyammahi, S. K., Alhamad, D. W. \& Omar, H. A. Tackling the cytokine storm in COVID-19, challenges and hopes. Life Sci. 257, (2020).

9. Polidoro, R. B., Hagan, R. S., de Santis Santiago, R. \& Schmidt, N. W. Overview: Systemic inflammatory response derived from lung injury caused by SARS-CoV-2 infection explains severe outcomes in COVID-19. Front. Immunol. 11, (2020). 
10. Vardhana, S. A. \& Wolchok, J. D. The many faces of the anti-COVID immune response. J. Exp. Med. 217, (2020).

11. Szabo, G. \& Petrasek, J. Inflammasome activation and function in liver disease. Nat. Rev. Gastroenterol. Hepatol. 12, 387-400 (2015).

12. Mangan, M. et al. Targeting the NLRP3 inflammasome in inflammatory diseases. Nat. Rev. Drug Discov. 17, 688 (2018).

13. Broz, P. \& Dixit, V. M. Inflammasomes: mechanism of assembly, regulation and signalling. Nat. Rev. Immunol. 16, 407-420 (2016).

14. Wang, $X$. et al. RNA viruses promote activation of the NLRP3 inflammasome through a RIP1-RIP3DRP1 signaling pathway. Nat. Immunol. 15, 1126-1133 (2014).

15. Pan, P. et al. Dengue virus M protein promotes NLRP3 inflammasome activation to induce vascular leakage in mice. J. Virol. 93(21), e00996-19 (2019).

16. Kelley, N., Jeltema, D., Duan, Y. \& He, Y. The NLRP3 inflammasome: an overview of mechanisms of activation and regulation. Int. J. Mol. Sci. 20(13), 3328. (2019).

17. Latz, E., Xiao, T. S. \& Stutz, A. Activation and regulation of the inflammasomes. Nat. Rev. Immunol. 13, 397-411 (2013).

18. Weber, A., Wasiliew, P. \& Kracht, M. Interleukin-1 (IL-1) pathway. Sci. Signal. 3(105), cm1 (2010).

19. Weber, A., Wasiliew, P. \& Kracht, M. Interleukin-1 beta (IL-1 beta) processing pathway. Sci. Signal. 3(105), cm2 (2010).

20. Ren, L. et al. Identification of a novel coronavirus causing severe pneumonia in human: a descriptive study. Chinese Med. J.-Peking. 133, 1015-1024 (2020).

21. Lu, R. et al. Genomic characterisation and epidemiology of 2019 novel coronavirus: implications for virus origins and receptor binding. Lancet. 395, 565-574 (2020).

22. Nieto-Torres, J. L. et al. Severe acute respiratory syndrome coronavirus E protein transports calcium ions and activates the NLRP3 inflammasome. Virology. 485, 330-339 (2015).

23. Chen, I. Y., Moriyama, M., Chang, M. F. \& Ichinohe, T. Severe Acute Respiratory Syndrome Coronavirus Viroporin 3a Activates the NLRP3 Inflammasome. Front. Microbiol. 10, 50 (2019).

24. Tay, Matthew Zirui et al. The trinity of COVID-19: immunity, inflammation and intervention. Nat Rev Immunol. 20(6), 363-374 (2020).

25. Mehta, P. et al. COVID-19: consider cytokine storm syndromes and immunosuppression. Lancet. 395, 1033-1034 (2020).

26. Zhang, F. et al. The caspase-1 inhibitor AC-YVAD-CMK attenuates acute gastric injury in mice: involvement of silencing NLRP3 inflammasome activities. Sci. Rep. 6, 24166 (2016).

27. Wang, W. et al. Zika virus infection induces host inflammatory responses by facilitating NLRP3 inflammasome assembly and interleukin-1beta secretion. Nat. Commun. 9, 106 (2018).

28. Kayagaki, N. et al. Noncanonical inflammasome activation by intracellular LPS independent of TLR4. Science. 341, 1246-1249 (2013). 
29. Li, H. et al. SARS-CoV-2 and viral sepsis: observations and hypotheses. Lancet. 395, 1517-1520 (2020).

30. Martinon, F., Mayor, A. \& Tschopp, J. The Inflammasomes: Guardians of the Body. Annu. Rev. Immunol. 27, 229-265 (2009).

31. Wang, H., Mao, L. \& Meng, G. The NLRP3 inflammasome activation in human or mouse cells, sensitivity causes puzzle. Protein Cell. 4, 565-568 (2013).

32. Cong, Y. et al. Nucleocapsid protein recruitment to replication-transcription complexes plays a crucial role in coronaviral life cycle. J. Virol. 94(4), e01925-19. (2020).

33. Peng, Y. et al. Structures of theSARS-CoV-2 nucleocapsid and their perspectives for drug design. EMBO J. 39(20), e105938 (2020).

34. Mu, J. et al. SARS-CoV-2-encoded nucleocapsid protein acts as a viral suppressor of RNA interference in cells. Sci. China Life Sci. 63, 1413-1416 (2020).

35. Ni, L. et al. Detection of SARS-CoV-2-specific humoral and cellular immunity in COVID-19 convalescent individuals. Immunity. 52, 971 (2020).

36. Slaats, J., Ten Oever, J., van de Veerdonk, F. L. \& Netea, M. G. IL-1 beta/IL-6/CRP and IL-18/ferritin: distinct inflammatory programs in infections. PLoS Pathog. 12(12), e1005973 (2016).

37. Pan, P. et al. Dengue virus infection activates interleukin-1 beta to induce tissue injury and vascular leakage. Front. Microbiol. 10, 2637 (2019).

38. Schett, G., Dayer, J. \& Manger, B. Interleukin-1 function and role in rheumatic disease. Nat. Rev. Rheumatol. 12, 14-24 (2016).

39. Chen G. et al. Clinical and immunological features of severe and moderate coronavirus disease 2019. J Clin Invest. 130(5), 2620-2629 (2020).

40. Wan, P. et al. Cullin1 binds and promotes NLRP3 ubiquitination to repress systematic inflammasome activation. Faseb J. 33, 5793-5807 (2019).

\section{Tables}

Table 1. qRT-PCR Primers used in this study. 


\begin{tabular}{|c|c|c|}
\hline Name & Forward & Reverse \\
\hline Human IL-1 $\beta$ & 5'-CACGATGCACCTGTACGATCA-3' & 5'-GTTGCTCCATATCCTGTCCCT-3' \\
\hline $\begin{array}{l}\text { Human } \\
\text { IL-6 }\end{array}$ & 5'-GTACATCCTCGACGGCATCTCA-3' & 5'-GCACAGCTCTGGCTTGTTCCTC-3' \\
\hline $\begin{array}{l}\text { Human } \\
\text { TNF-a }\end{array}$ & 5'-TCTCGAACCCCGAGTGACA-3' & 5'-GCCCGGCGGTTCA-3' \\
\hline Human CXCL10 & 5'-ACTGTACGCTGTACCTGCAT-3' & 5'-ACACGTGGACAAAATTGGCT-3' \\
\hline Human GAPDH & 5'AAGGCTGTGGGCAAGG-3' & 5'-TGGAGGAGTGGGTGTCG-3' \\
\hline $\begin{array}{l}\text { Human } \\
\text { IL-11 }\end{array}$ & 5'-GAACTGTGTTTGCCGCCTGG-3' & 5'-GTCTGGGGAAACTCGAGGGG-3' \\
\hline $\begin{array}{l}\text { Human } \\
\text { IL-13 }\end{array}$ & 5'-CATGGCGCTTTTGTTGACCA-3' & 5'-AGCTGTCAGGTTGATGCTCC-3' \\
\hline $\begin{array}{l}\text { Human } \\
\text { CCL2 }\end{array}$ & 5'-TGCAATCAATGCCCCAGTCA-3' & 5'-GGGTCAGCACAGATCTCCTT-3' \\
\hline $\begin{array}{l}\text { Human } \\
\text { CXCL8 }\end{array}$ & 5'-CAGTTTTGCCAAGGAGTGCT-3' & 5'-GTTTTCCTTGGGGTCCAGACA-3' \\
\hline $\begin{array}{l}\text { Human } \\
\text { IL-18 }\end{array}$ & 5'-ACGCTTTACTTTATAGCTGAAGATG-3' & 5'-GAGGCCGATTTCCTTGGTCA-3' \\
\hline $\begin{array}{l}\text { Human } \\
\text { IL-10 }\end{array}$ & 5'-AGGCAACCTGCCTAACATGC-3' & 5'-GTTCTCAGCTTGGGGCATCA-3' \\
\hline $\begin{array}{l}\text { Human } \\
\text { VEGFA }\end{array}$ & 5'-TGCGGATCAAACCTCACCAA-3' & 5'-ACCAACGTACACGCTCCAG-3' \\
\hline $\begin{array}{l}\text { Mice } \\
\text { IL-1 } \beta\end{array}$ & 5'-TGCCACCTTTTGACAGTGATG-3' & 5'-TGTGCTGCTGCGAGATTTGA-3' \\
\hline $\begin{array}{l}\text { Mice } \\
\text { IL-6 }\end{array}$ & 5'-AGACAAAGCCAGAGTCCTTCAGAGA-3' & 5'-GCCACTCCTTCTGTGACTCCAGC-3' \\
\hline $\begin{array}{l}\text { Mice } \\
\text { TNF-a }\end{array}$ & 5'-ACGTGGAACTGGCAGAAGAG-3' & 5'-CTCCTCCACTTGGTGGTTTG-3' \\
\hline $\begin{array}{l}\text { Mice } \\
\text { CXCL10 }\end{array}$ & 5'-GTGCTGCCGTCATTTTCTGC-3' & 5'-AAGCTTCCCTATGGCCCTCA-3' \\
\hline
\end{tabular}


CCL2

Mice

5'-GAACTGTGTTTGTCGCCTGG-3'

5'-TGCTCGAGGGTCTGAAGAGA-3'

IL-11

Mice

5'-GAGGCCGATTTCCTTGGTCA-3'

5'-GAGGCCGATTTCCTTGGTCA-3'

IL-1 $\beta$

Mice

5'-CCCACGTCAGAGAGCAACAT-3'

5'-TGCGCTTTCGTTTTTGACCC-3'

VEGFA

Mice

5'-CGATGAATTGGACAAAATGACAGG-3'

5'-TGCGAGCAGCACGATTTAGA-3'

IL-7

Mice

5'-CCTGATGCTCCATGGGTGAA-3'

5'-ACAGAAGCTTCATTGCCGGT-3'

CXCL8

Mice

5'-CTCAGTTTGGCCAGGGTCAT-3'

5'-GTCTTCAGCAGGTTTCGGGA-3'

IL-12A

Mice

5'-TCAGACAACTTTGGCCGACT-3'

5'-CAGTCTGGTCTGGGGTTCAC-3'

IL-18

Mice

5'-GGGCTGTGTCAGTGTAGGTC-3'

5'-TGCAATTCCAGGAGAAAGCAG-3'

IL-15

Mice

5'-GCATGGCCCAGAAATCAAGG-3'

5'-GAGAAATCGATGACAGCGCC-3'

IL-10

Mice

5'-AGAGGGAAATCGTGCGTGAC-3'

5'-CAATAGTGATGACCTGGCCGT-3'

$\beta$-actin

Table 2. Clone Primers used in this study. 


\begin{tabular}{|c|c|c|}
\hline Name & Forward & Reverse \\
\hline N1 & $\begin{array}{l}\text { 5'-GCGGATCCATGTCTGATAATGGACCCCAA- } \\
3^{\prime}\end{array}$ & $\begin{array}{l}\text { 5'-GCTCTAGATTAAATGCGCGACATTCCGA- } \\
3^{\prime}\end{array}$ \\
\hline N2 & $\begin{array}{l}\text { 5'-GCGGATCCATGTCTGATAATGGACCCCAA- } \\
3^{\prime}\end{array}$ & $\begin{array}{l}\text { 5'-GCTCTAGATTATTGCCGAGGCTTCTTAG- } \\
3^{\prime}\end{array}$ \\
\hline N3 & $\begin{array}{l}\text { 5'-GCGGATCCATGTCTGATAATGGACCCCAA- } \\
3^{\prime} \text { ' }\end{array}$ & 5'-GCTCTAGATTAACTGCCGCCTCTGCTC-3' \\
\hline N4 & $\begin{array}{l}\text { 5'-GCGGATCCATGTCTGATAATGGACCCCAA- } \\
3^{\prime}\end{array}$ & $\begin{array}{l}\text { 5'-CGTCTAGATTAAGCTCTTCGGTAGTAGC- } \\
3^{\prime}\end{array}$ \\
\hline N5 & 5'-GCGGATCCATGACCAGACGAATTCG-3' & 5'-GCTCTAGATTAGGCCTGAGTTGAGTC-3' \\
\hline N6 & 5'-GCGGATCCATGCAAGCCTCTTCTCGT-3' & 5'-GCTCTAGATTAGGCCTGAGTTGAGTC-3' \\
\hline N7 & 5'-GCGGATCCATGAAACGTACTGCCAC-3' & 5'-GCTCTAGATTAGGCCTGAGTTGAGTC-3' \\
\hline N8 & 5'-GCGGATCCATGGACAAAGATCCAAA-3' & 5'-GCTCTAGATTAGGCCTGAGTTGAGTC-3' \\
\hline
\end{tabular}

\section{Figures}


a

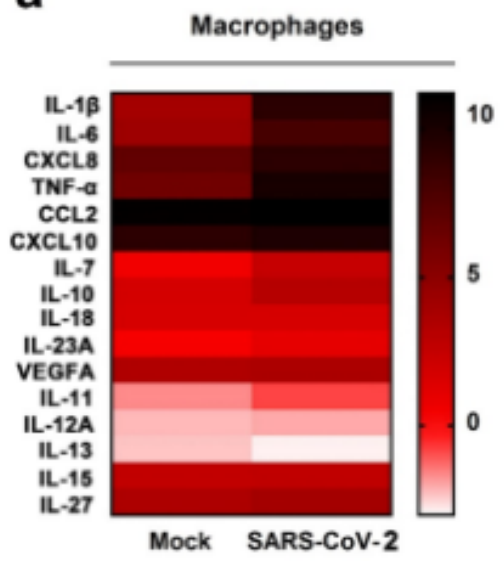

d

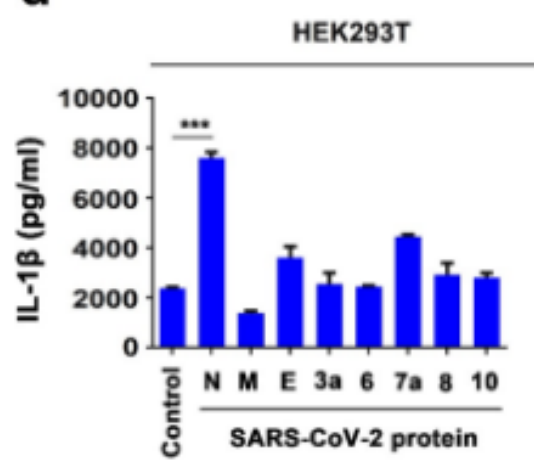

g

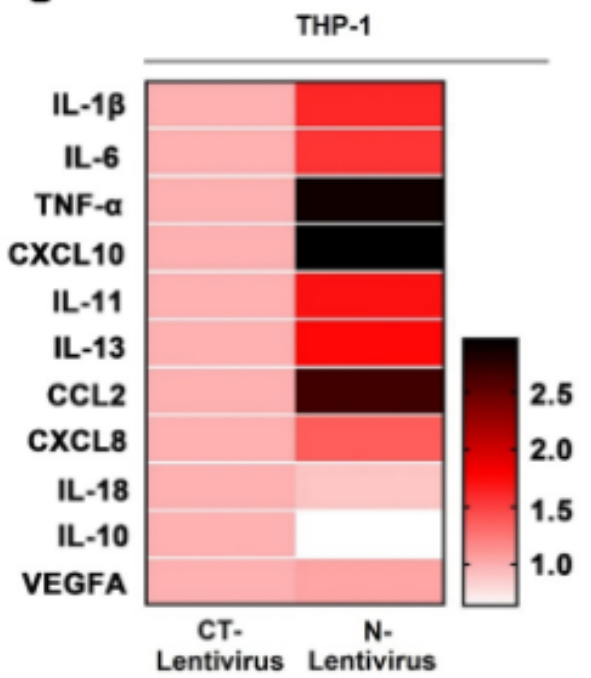

b

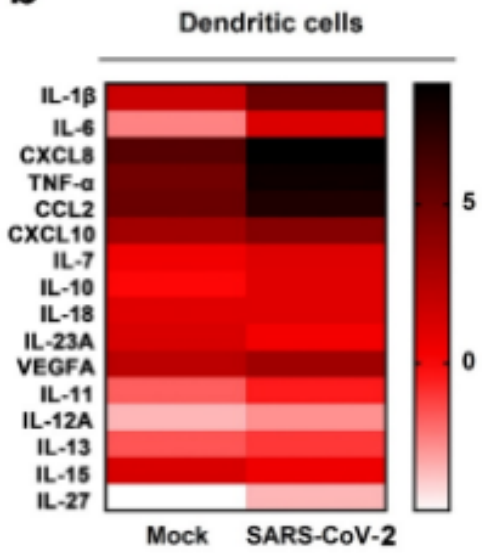

e

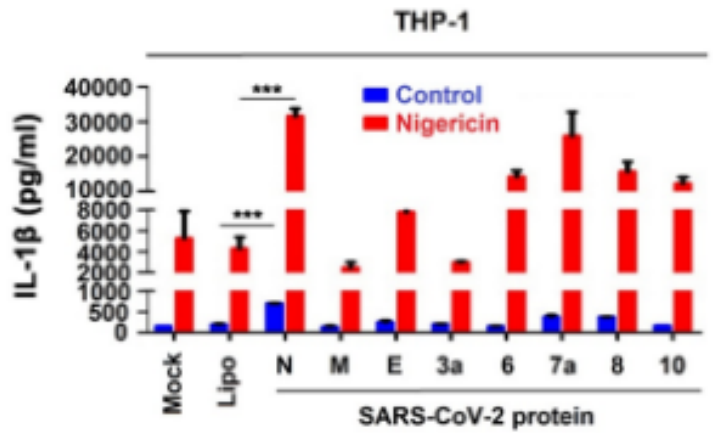

h

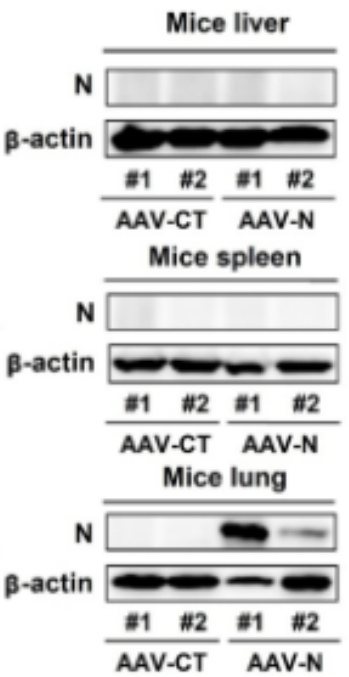

C

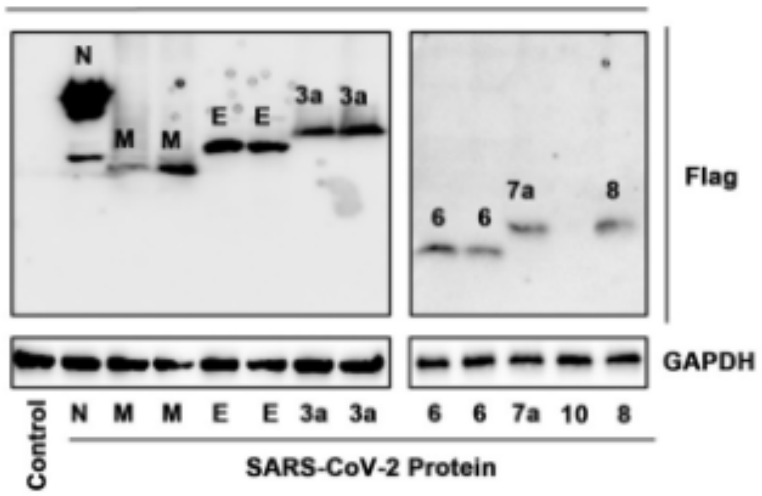

f

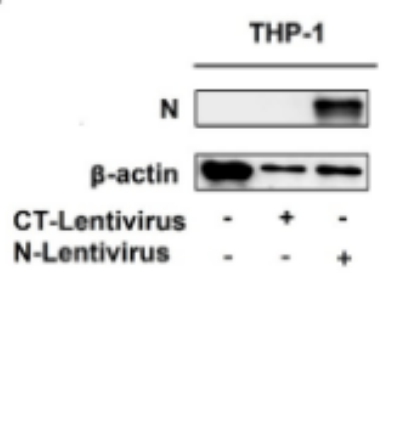

\section{Figure 1}

i

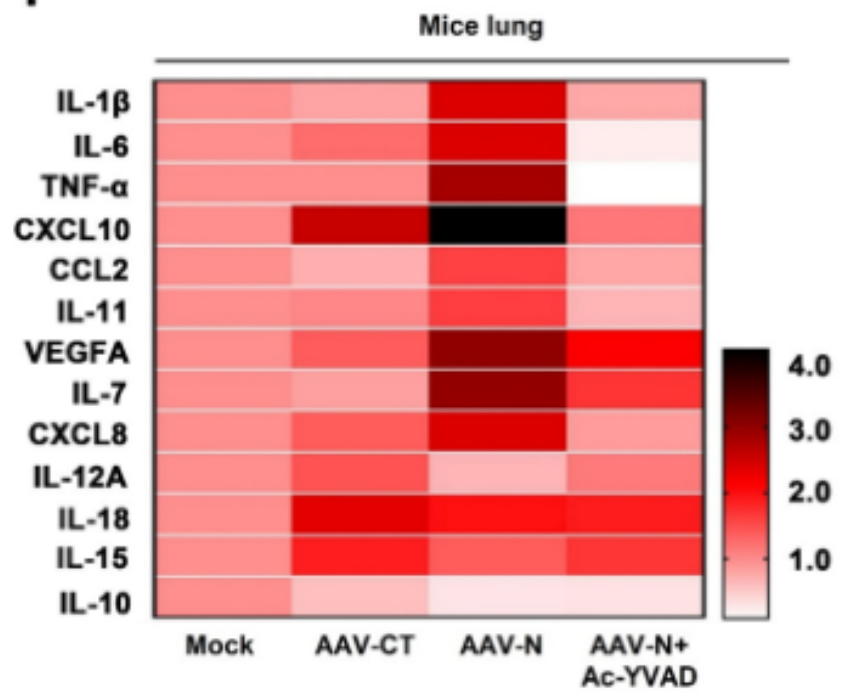

SARS-CoV-2 $\mathrm{N}$ protein induces proinflammatory responses in cells and mice tissues. $(\mathrm{a}, \mathrm{b})$ Transcriptional level of indicated gene in macrophage (a) and dendritic cells (b) infected with SARS-CoV-2 (GSE155106, RNA-Seq data from GEO database) were analyzed and the values were showed in logarithmic form. (c) HEK293T cells were transfected with plasmids encoding N, M, E, 3a, 6, 7a, 8, 10 for $24 \mathrm{~h}$. The indicated proteins in cell extract were analyzed by WB. (d) HEK293T cells were co-transfected with plasmids 
encoding NLRP3, ASC, pro-Casp1, or pro-IL-1 $\beta$, and transfected with plasmids encoding N, M, E, 3a, 6, 7a, 8, and 10 for $48 \mathrm{~h}$. Supernatants were analyzed by ELISA for IL-1 $\beta$. (e) PMA-differentiated THP-1 macrophages were transfected with plasmids encoding $N, M, E, 3 a, 6,7 a, 8$, and 10 for $48 \mathrm{~h}$, and then stimulated with $2 \mu \mathrm{M}$ Nigericin or DMSO for $2 \mathrm{~h}$. IL-1 $\beta$ in cell supernatants was measured by ELISA. (f, $g$ ) THP-1 cells were stably infected with Lentivirus-CT or Lentivirus-N, differentiated into macrophages. Cell lysates were analyzed by immunoblotting ( $\mathrm{f}$ ). The indicated gene mRNA was quantified by qRT-PCR (g). $(\mathrm{h}, \mathrm{i})$ C57BL/ 6 genetic background mice were tail vein injection with $300 \mu \mathrm{l}$ containing $5 \times 1011 \mathrm{vg}$ of AAV-Lung-EGFP $(n=8)$ or AAV-Lung-N $(n=16)$, after two weeks, treated with Ac-YVAD-cmk $(8 \mathrm{mg} / \mathrm{kg})$ by intraperitoneal injection for AAV-Lung-N $(n=8)$ mice, after three weeks, two mice for each group were euthanasia, and the Lung were collected. The indicated proteins were analyzed by WB (h). The indicated gene mRNA was quantified by qRT-PCR (i). Mock means healthy donors ( $a$ and b), untreated cells (e) and injection of the same dose of PBS (i). Control means transfected with empty plasmids (c, d). Lipo means transfection with reagents Lipo2000 (e). Date were representative of three independent experiments. Values are mean \pm SEM. $P \leq 0.05(*), P \leq 0.01(* *), P \leq 0.001\left(^{(* *)}\right.$. 
a

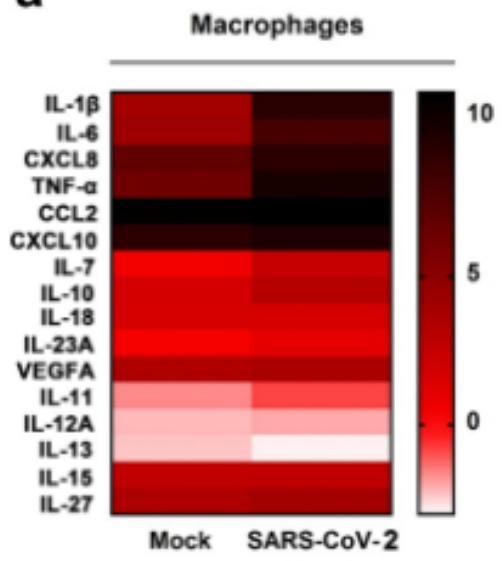

d

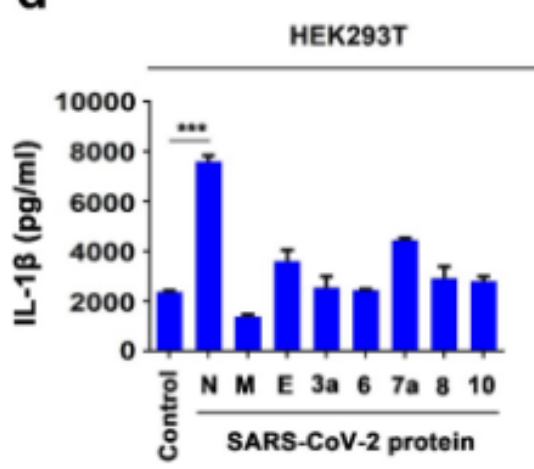

g

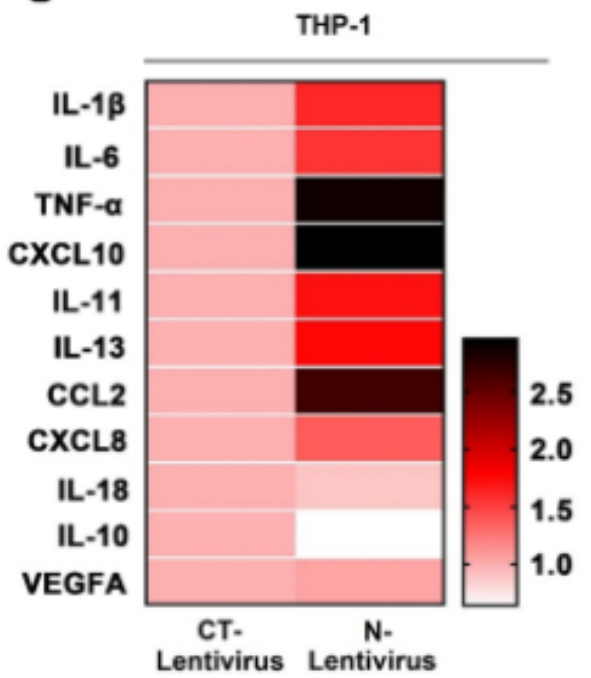

b

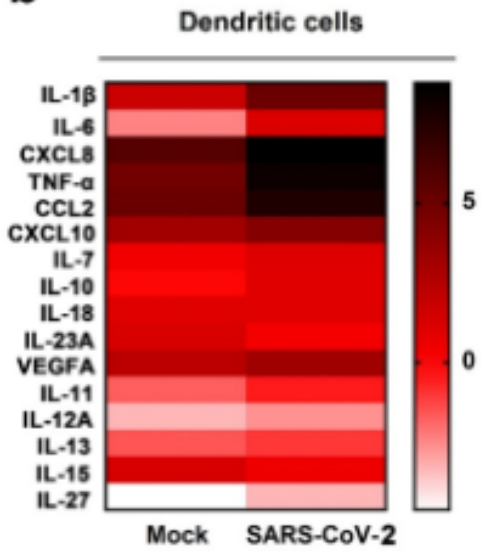

e

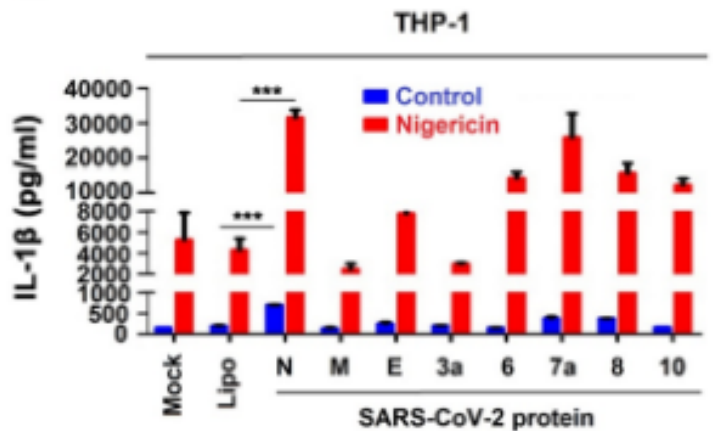

h

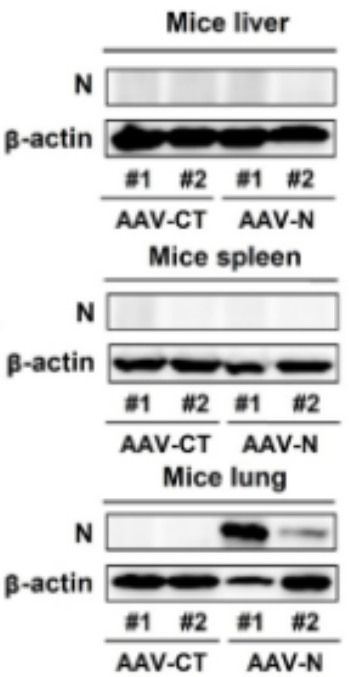

C

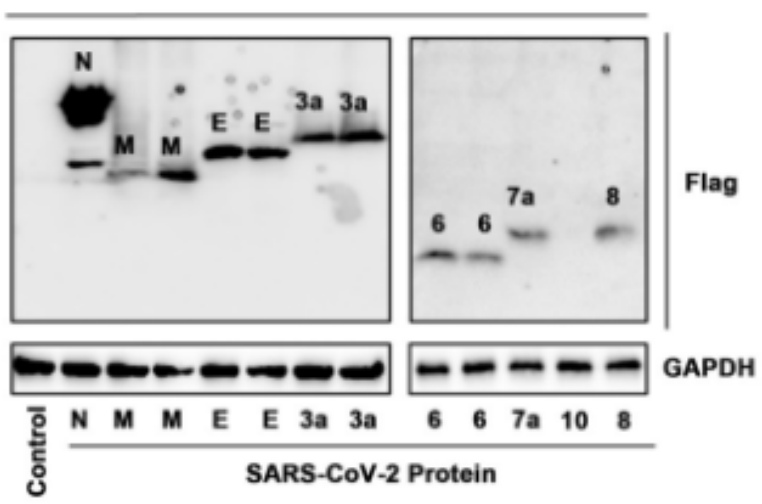

f

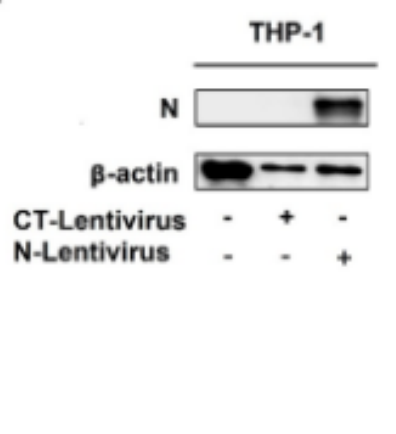

\section{Figure 1}

i

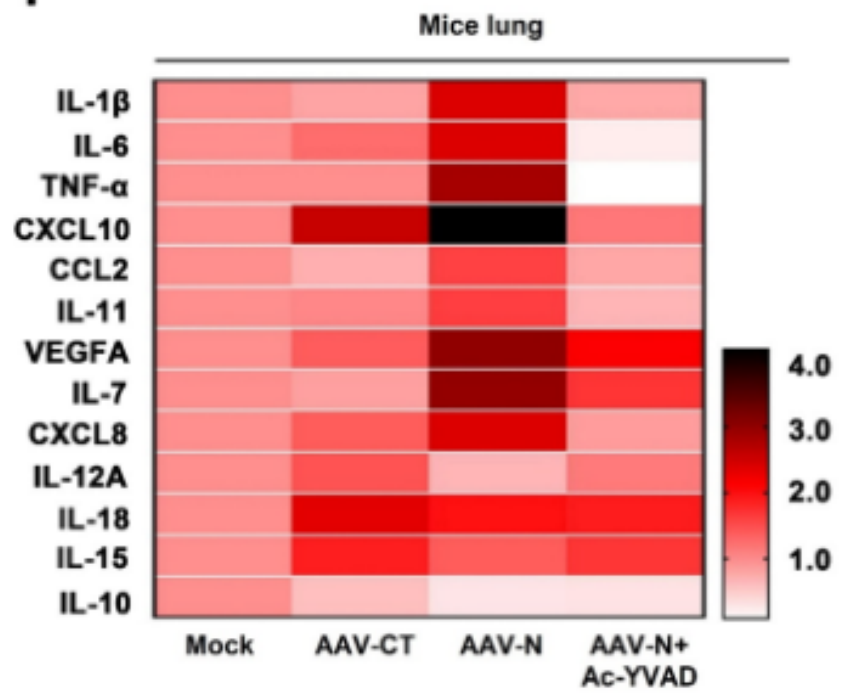

SARS-CoV-2 $\mathrm{N}$ protein induces proinflammatory responses in cells and mice tissues. $(a, b)$ Transcriptional level of indicated gene in macrophage (a) and dendritic cells (b) infected with SARS-CoV-2 (GSE155106, RNA-Seq data from GEO database) were analyzed and the values were showed in logarithmic form. (c) HEK293T cells were transfected with plasmids encoding N, M, E, 3a, 6, 7a, 8, 10 for $24 \mathrm{~h}$. The indicated proteins in cell extract were analyzed by WB. (d) HEK293T cells were co-transfected with plasmids 
encoding NLRP3, ASC, pro-Casp1, or pro-IL-1 $\beta$, and transfected with plasmids encoding N, M, E, 3a, 6, 7a, 8, and 10 for $48 \mathrm{~h}$. Supernatants were analyzed by ELISA for IL-1 $\beta$. (e) PMA-differentiated THP-1 macrophages were transfected with plasmids encoding $N, M, E, 3 a, 6,7 a, 8$, and 10 for $48 \mathrm{~h}$, and then stimulated with $2 \mu \mathrm{M}$ Nigericin or DMSO for $2 \mathrm{~h}$. IL-1 $\beta$ in cell supernatants was measured by ELISA. (f, $g$ ) THP-1 cells were stably infected with Lentivirus-CT or Lentivirus-N, differentiated into macrophages. Cell lysates were analyzed by immunoblotting ( $\mathrm{f}$ ). The indicated gene mRNA was quantified by qRT-PCR (g). $(\mathrm{h}, \mathrm{i})$ C57BL/ 6 genetic background mice were tail vein injection with $300 \mu \mathrm{l}$ containing $5 \times 1011 \mathrm{vg}$ of AAV-Lung-EGFP $(n=8)$ or AAV-Lung-N $(n=16)$, after two weeks, treated with Ac-YVAD-cmk $(8 \mathrm{mg} / \mathrm{kg})$ by intraperitoneal injection for AAV-Lung-N $(n=8)$ mice, after three weeks, two mice for each group were euthanasia, and the Lung were collected. The indicated proteins were analyzed by WB (h). The indicated gene mRNA was quantified by qRT-PCR (i). Mock means healthy donors ( $a$ and b), untreated cells (e) and injection of the same dose of PBS (i). Control means transfected with empty plasmids (c, d). Lipo means transfection with reagents Lipo2000 (e). Date were representative of three independent experiments. Values are mean \pm SEM. $P \leq 0.05(*), P \leq 0.01(* *), P \leq 0.001\left(^{(* *)}\right.$. 

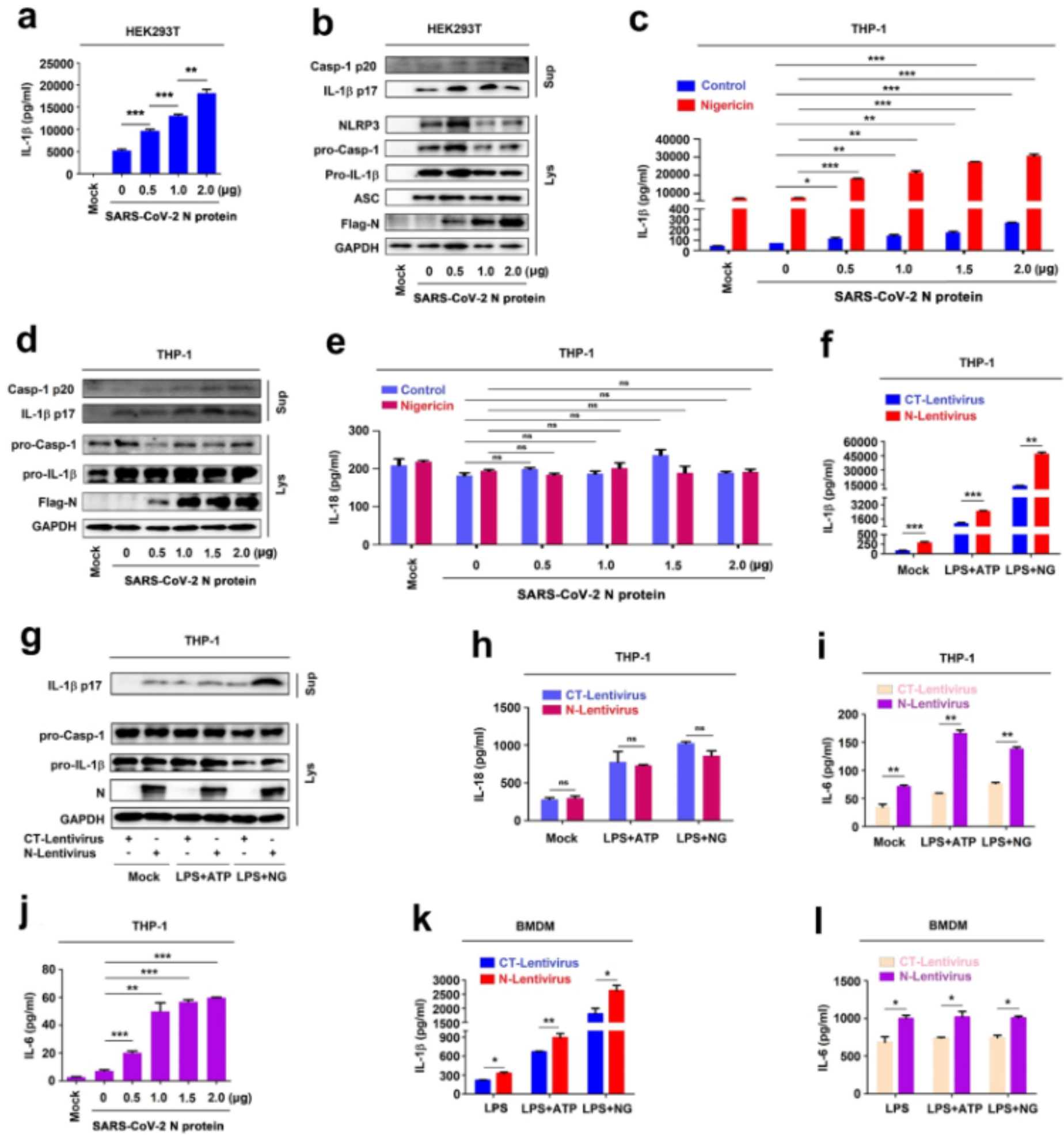

\section{Figure 2}

SARS-CoV-2 $\mathrm{N}$ protein induces proinflammatory responses in cells and mice tissues. $(a, b)$ Transcriptional level of indicated gene in macrophage (a) and dendritic cells (b) infected with SARS-CoV-2 (GSE155106, RNA-Seq data from GEO database) were analyzed and the values were showed in logarithmic form. (c) HEK293T cells were transfected with plasmids encoding N, M, E, 3a, 6, 7a, 8, 10 for $24 \mathrm{~h}$. The indicated proteins in cell extract were analyzed by WB. (d) HEK293T cells were co-transfected with plasmids 
encoding NLRP3, ASC, pro-Casp1, or pro-IL-1 $\beta$, and transfected with plasmids encoding N, M, E, 3a, 6, 7a, 8, and 10 for $48 \mathrm{~h}$. Supernatants were analyzed by ELISA for IL-1 $\beta$. (e) PMA-differentiated THP-1 macrophages were transfected with plasmids encoding $N, M, E, 3 a, 6,7 a, 8$, and 10 for $48 \mathrm{~h}$, and then stimulated with $2 \mu \mathrm{M}$ Nigericin or DMSO for $2 \mathrm{~h}$. IL-1 $\beta$ in cell supernatants was measured by ELISA. (f, $g$ ) THP-1 cells were stably infected with Lentivirus-CT or Lentivirus-N, differentiated into macrophages. Cell lysates were analyzed by immunoblotting ( $\mathrm{f}$ ). The indicated gene mRNA was quantified by qRT-PCR (g). $(\mathrm{h}, \mathrm{i})$ C57BL/ 6 genetic background mice were tail vein injection with $300 \mu \mathrm{l}$ containing $5 \times 1011 \mathrm{vg}$ of AAV-Lung-EGFP $(n=8)$ or AAV-Lung-N $(n=16)$, after two weeks, treated with Ac-YVAD-cmk $(8 \mathrm{mg} / \mathrm{kg})$ by intraperitoneal injection for AAV-Lung-N $(n=8)$ mice, after three weeks, two mice for each group were euthanasia, and the Lung were collected. The indicated proteins were analyzed by WB (h). The indicated gene mRNA was quantified by qRT-PCR (i). Mock means healthy donors ( $a$ and b), untreated cells (e) and injection of the same dose of PBS (i). Control means transfected with empty plasmids (c, d). Lipo means transfection with reagents Lipo2000 (e). Date were representative of three independent experiments. Values are mean \pm SEM. $P \leq 0.05(*), P \leq 0.01(* *), P \leq 0.001\left(^{(* *)}\right.$. 

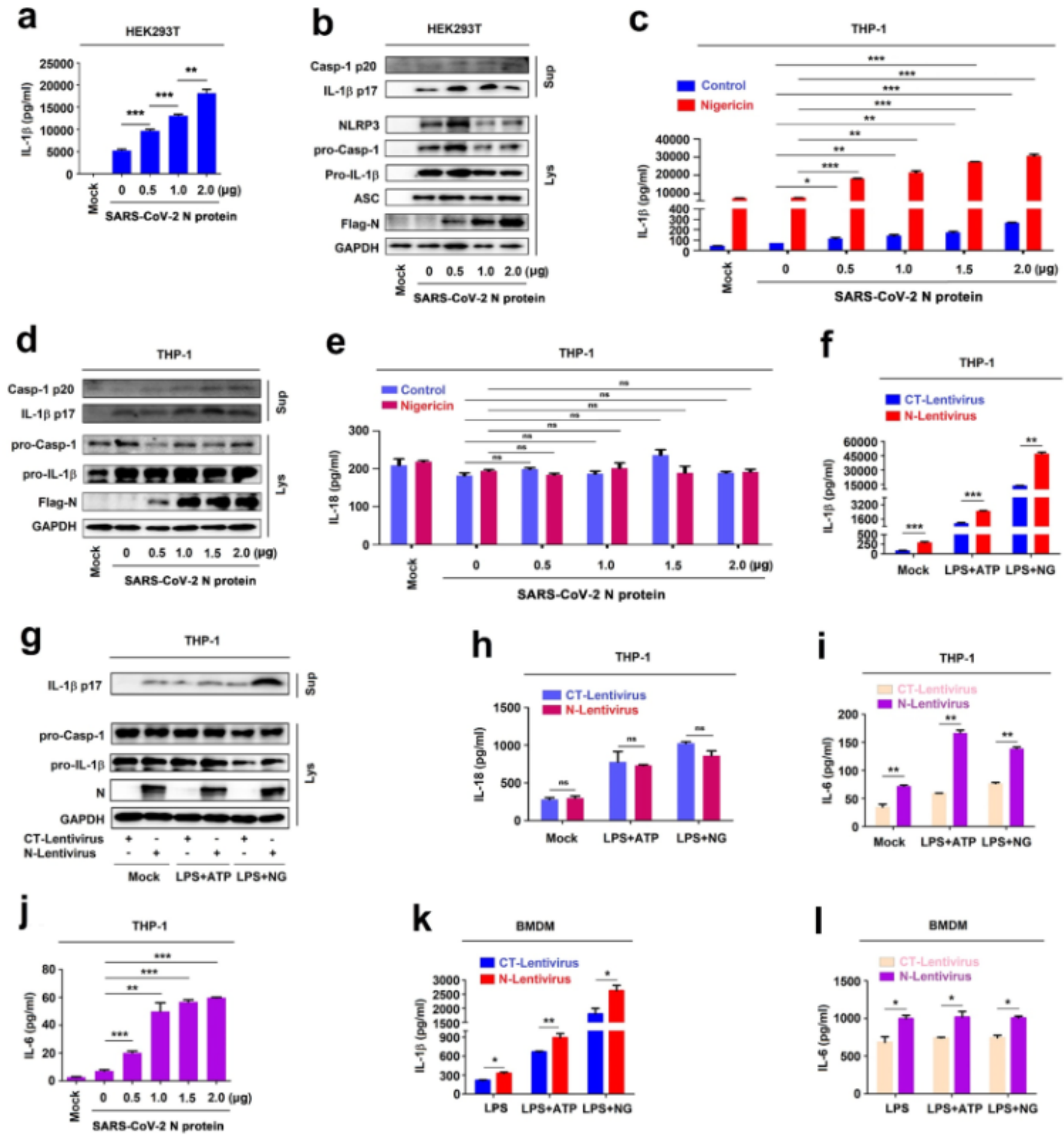

\section{Figure 2}

SARS-CoV-2 $\mathrm{N}$ protein induces proinflammatory responses in cells and mice tissues. $(a, b)$ Transcriptional level of indicated gene in macrophage (a) and dendritic cells (b) infected with SARS-CoV-2 (GSE155106, RNA-Seq data from GEO database) were analyzed and the values were showed in logarithmic form. (c) HEK293T cells were transfected with plasmids encoding N, M, E, 3a, 6, 7a, 8, 10 for $24 \mathrm{~h}$. The indicated proteins in cell extract were analyzed by WB. (d) HEK293T cells were co-transfected with plasmids 
encoding NLRP3, ASC, pro-Casp1, or pro-IL-1 $\beta$, and transfected with plasmids encoding N, M, E, 3a, 6, 7a, 8, and 10 for $48 \mathrm{~h}$. Supernatants were analyzed by ELISA for IL-1 $\beta$. (e) PMA-differentiated THP-1 macrophages were transfected with plasmids encoding $\mathrm{N}, \mathrm{M}, \mathrm{E}, 3 \mathrm{a}, 6,7 \mathrm{a}, 8$, and 10 for $48 \mathrm{~h}$, and then stimulated with $2 \mu \mathrm{M}$ Nigericin or DMSO for $2 \mathrm{~h}$. IL-1 $\beta$ in cell supernatants was measured by ELISA. (f, g) THP-1 cells were stably infected with Lentivirus-CT or Lentivirus-N, differentiated into macrophages. Cell lysates were analyzed by immunoblotting $(\mathrm{f})$. The indicated gene mRNA was quantified by qRT-PCR ( $\mathrm{g}$ ). $(h, i)$ C57BL/ 6 genetic background mice were tail vein injection with $300 \mu$ l containing $5 \times 1011 \mathrm{vg}$ of AAV-Lung-EGFP $(n=8)$ or AAV-Lung-N $(n=16)$, after two weeks, treated with Ac-YVAD-cmk $(8 \mathrm{mg} / \mathrm{kg}) \mathrm{by}$ intraperitoneal injection for AAV-Lung-N ( $n=8)$ mice, after three weeks, two mice for each group were euthanasia, and the Lung were collected. The indicated proteins were analyzed by WB (h). The indicated gene mRNA was quantified by qRT-PCR (i). Mock means healthy donors (a and b), untreated cells (e) and injection of the same dose of PBS (i). Control means transfected with empty plasmids (c, d). Lipo means transfection with reagents Lipo2000 (e). Date were representative of three independent experiments.

Values are mean \pm SEM. $P \leq 0.05\left(^{*}\right), P \leq 0.01(* *), P \leq 0.001(* * *)$.

a

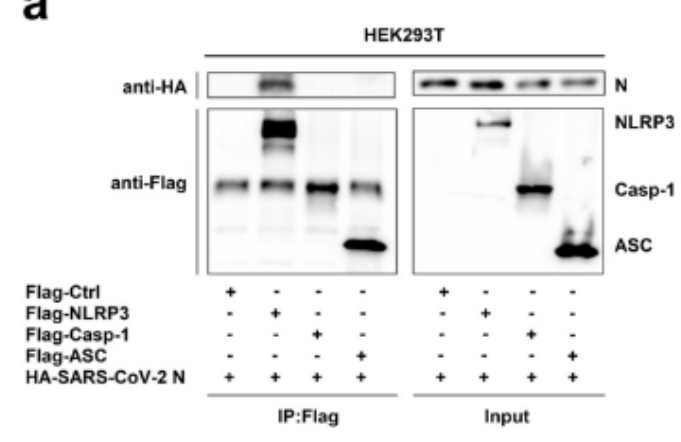

C

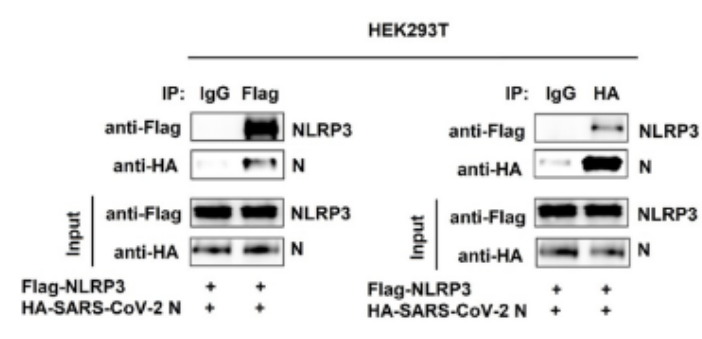

d

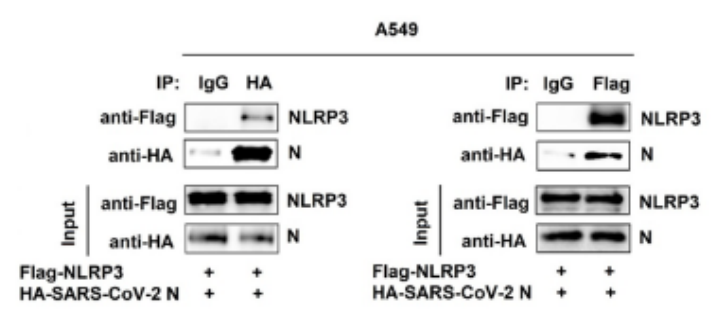

b
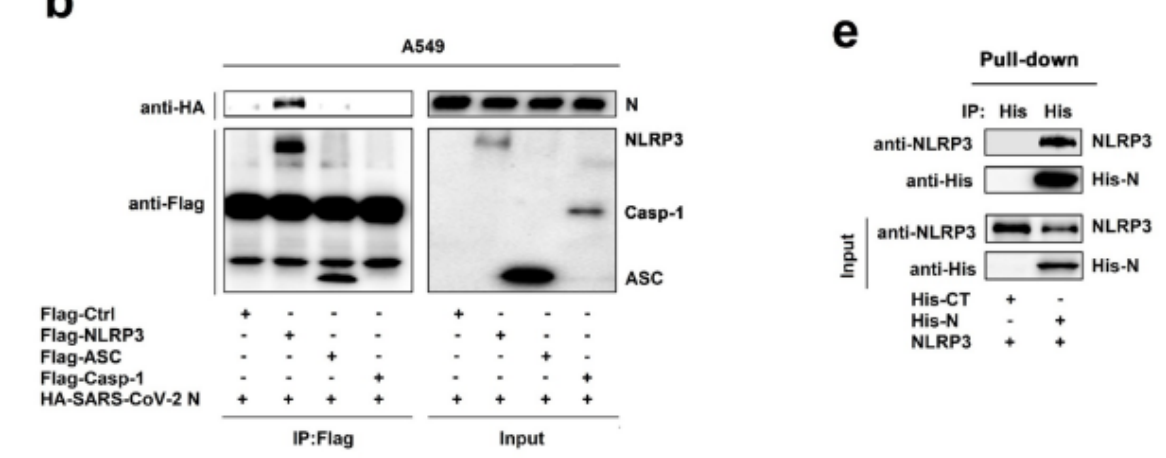

f

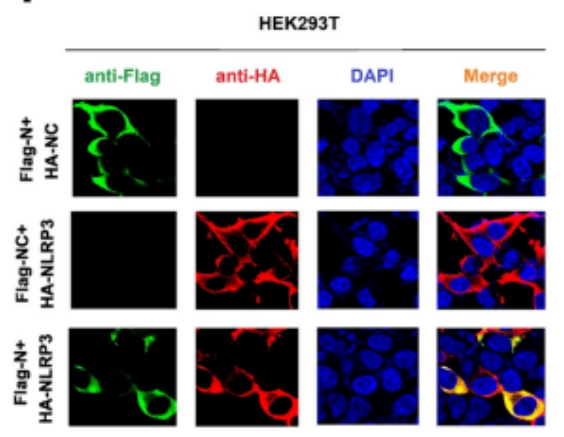

h

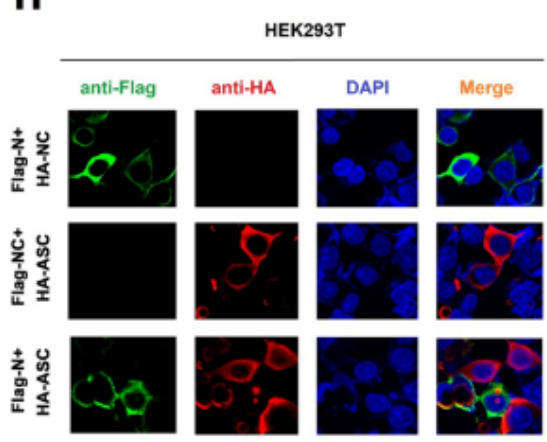

g

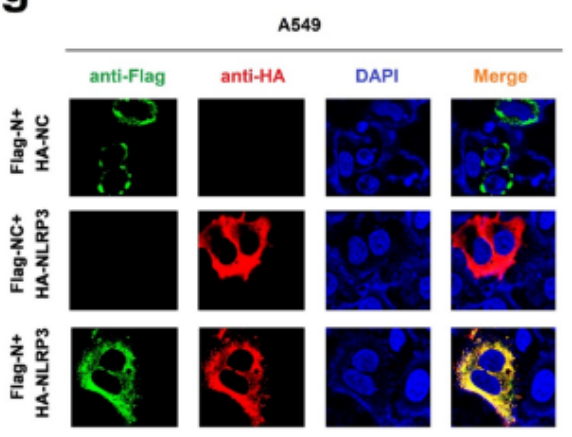

i

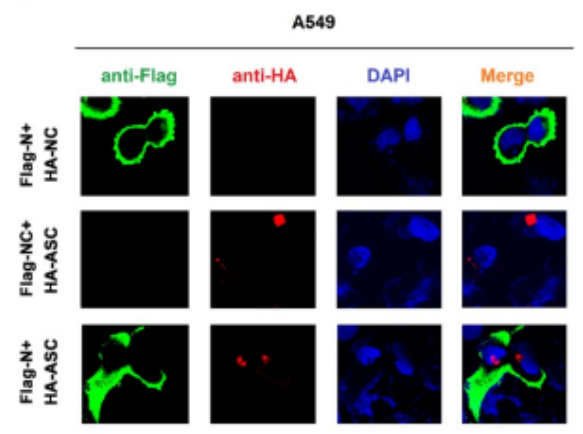

Figure 3 
SARS-CoV-2 N protein interacts with NLRP3 protein. $(a, b)$ HEK293T cells (a) or A549 cells (b) were cotransfected with HA-SARS-CoV-2-N and Flag-ctrl, Flag-NLRP3, Flag-pro-Casp-1, or Flag-ASC. Cell lysates were immunoprecipitated using anti-Flag antibody, and analyzed using anti-Flag and anti-HA antibody. Cell lysates $(40 \mu \mathrm{g}$ ) was used as Input. (c, d) HEK293T cells (c) or A549 cells (d) were co-transfected with Flag-NLRP3 and HA-SARS-CoV-2-N. Cell lysates were immunoprecipitated using anti-Flag antibody or anti-HA antibody, and analyzed using anti-Flag and anti-HA antibody. Cell lysates $(40 \mu \mathrm{g})$ was used as Input. (e) Purified His-CT $(10 \mu \mathrm{g})$ or His-N $(10 \mu \mathrm{g})$ was incubated with cell lysates of Flag-NLRP3transfected HEK293T cells. cell extracts were incubated with Ni-NTA Agarose beads. Mixtures were analyzed by immunoblotting using anti-NLRP3 or anti-His antibody. Untreated protein includes His-SARSCoV-2-N $(1 \mu \mathrm{g})$, His-CT $(1 \mu \mathrm{g})$ or HEK293T cell lysates were analyzed by immunoblotting (as input). ( $\mathrm{f}-\mathrm{i})$ HEK293T cells $(f, h)$ or A549 cells $(g, i)$ were transfected with Flag-SARS-CoV-2-N and HA-NLRP3 or HAASC for 24 h. Nucleus marker DAPI (blue), Flag-SARS-CoV-2-N (green) and HA-NLRP3 or HA-ASC (red) were then visualized with confocal microscopy. Flag-Ctrl, Flag-NC, or HA-NC means pcDNA3.1(+)-3×flag or pCAGGS-HA empty plasmid. Data were representative of three independent experiments.

a

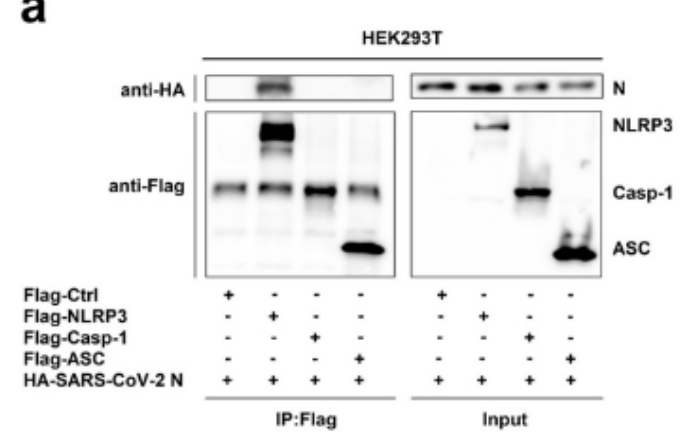

C

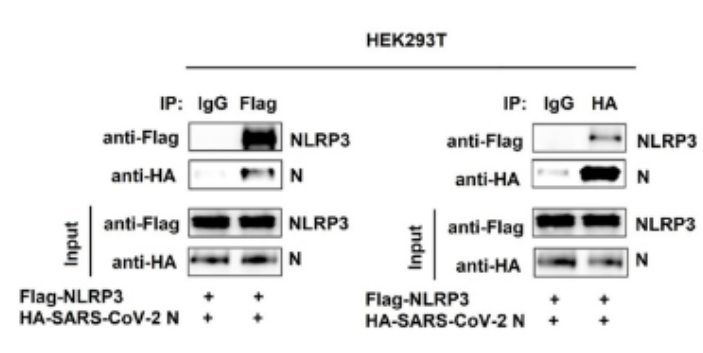

d

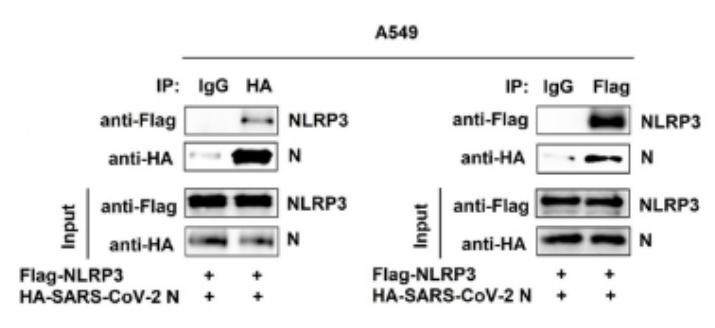

b
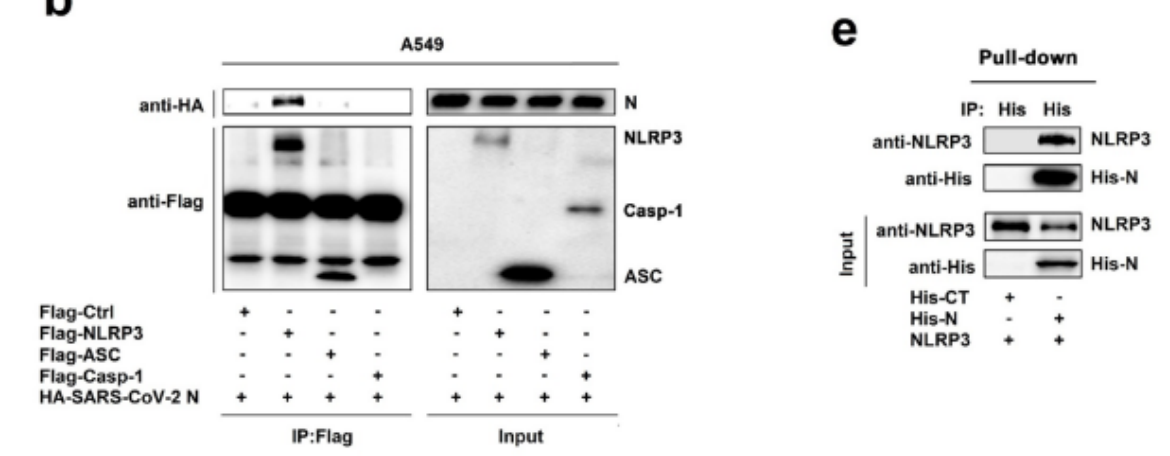

f

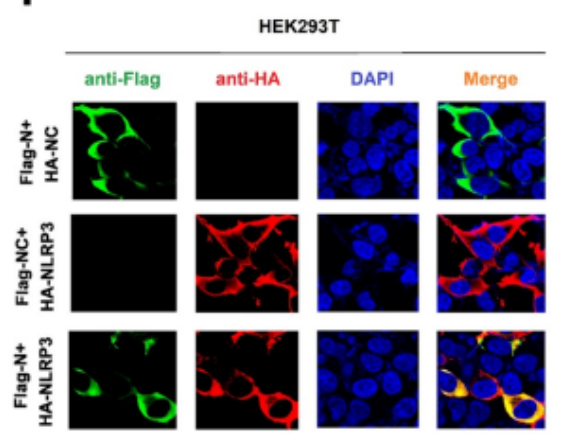

h

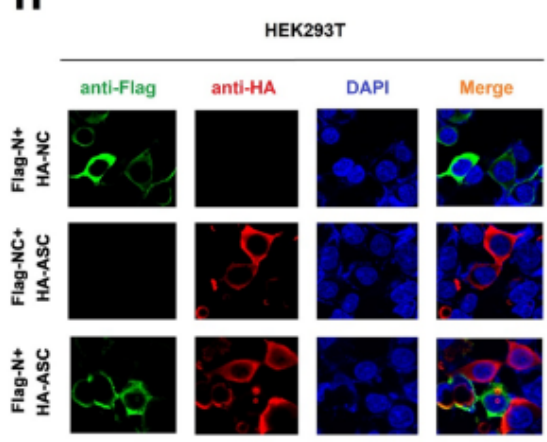

g

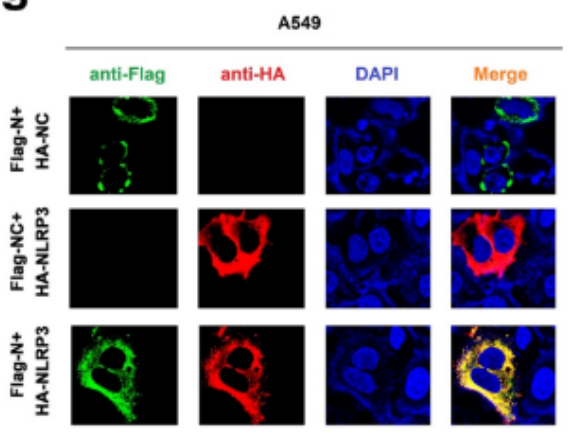

i

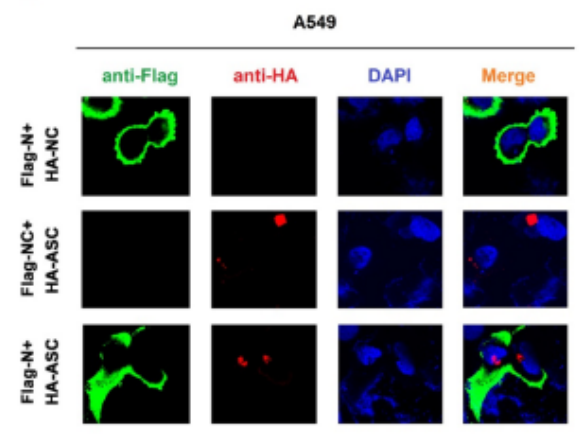

Figure 3 
SARS-CoV-2 N protein interacts with NLRP3 protein. $(a, b)$ HEK293T cells (a) or A549 cells (b) were cotransfected with HA-SARS-CoV-2-N and Flag-ctrl, Flag-NLRP3, Flag-pro-Casp-1, or Flag-ASC. Cell lysates were immunoprecipitated using anti-Flag antibody, and analyzed using anti-Flag and anti-HA antibody. Cell lysates $(40 \mu \mathrm{g})$ was used as Input. (c, d) HEK293T cells (c) or A549 cells (d) were co-transfected with Flag-NLRP3 and HA-SARS-CoV-2-N. Cell lysates were immunoprecipitated using anti-Flag antibody or anti-HA antibody, and analyzed using anti-Flag and anti-HA antibody. Cell lysates $(40 \mu \mathrm{g})$ was used as Input. (e) Purified His-CT $(10 \mu \mathrm{g})$ or His-N $(10 \mu \mathrm{g})$ was incubated with cell lysates of Flag-NLRP3transfected HEK293T cells. cell extracts were incubated with Ni-NTA Agarose beads. Mixtures were analyzed by immunoblotting using anti-NLRP3 or anti-His antibody. Untreated protein includes His-SARSCoV-2-N $(1 \mu \mathrm{g})$, His-CT $(1 \mu \mathrm{g})$ or HEK293T cell lysates were analyzed by immunoblotting (as input). ( $\mathrm{f}-\mathrm{i})$ HEK293T cells $(f, h)$ or A549 cells $(g, i)$ were transfected with Flag-SARS-CoV-2-N and HA-NLRP3 or HAASC for 24 h. Nucleus marker DAPI (blue), Flag-SARS-CoV-2-N (green) and HA-NLRP3 or HA-ASC (red) were then visualized with confocal microscopy. Flag-Ctrl, Flag-NC, or HA-NC means pcDNA3.1(+)-3×flag or pCAGGS-HA empty plasmid. Data were representative of three independent experiments.

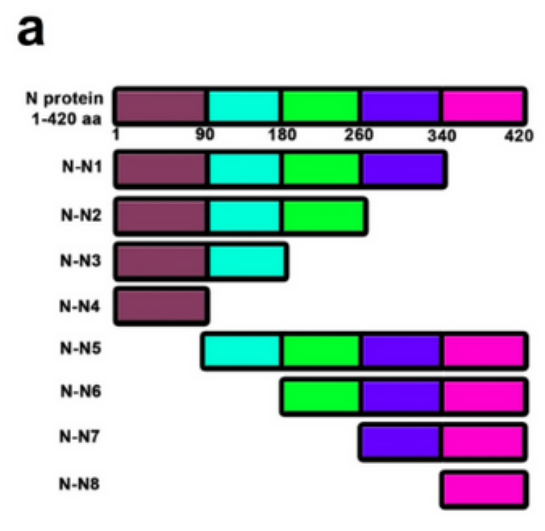

b

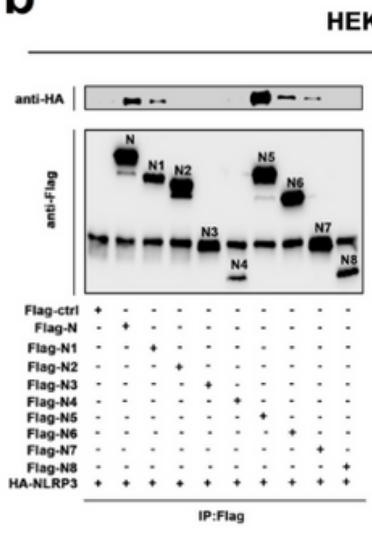

C

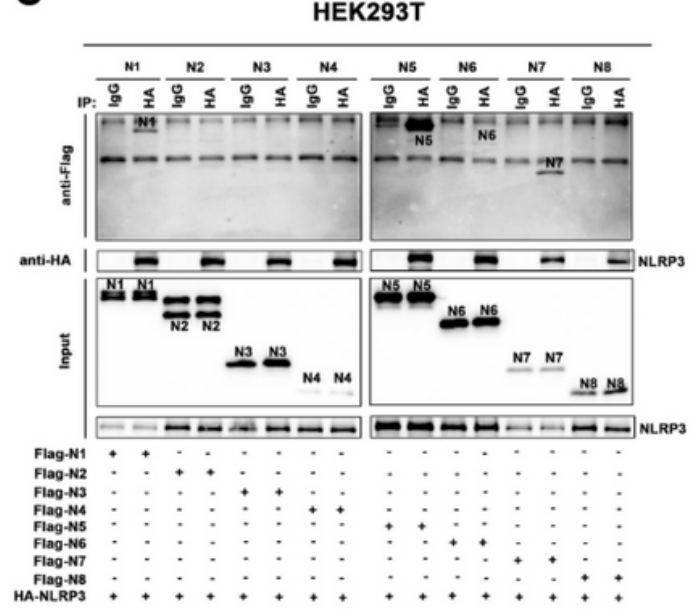

e

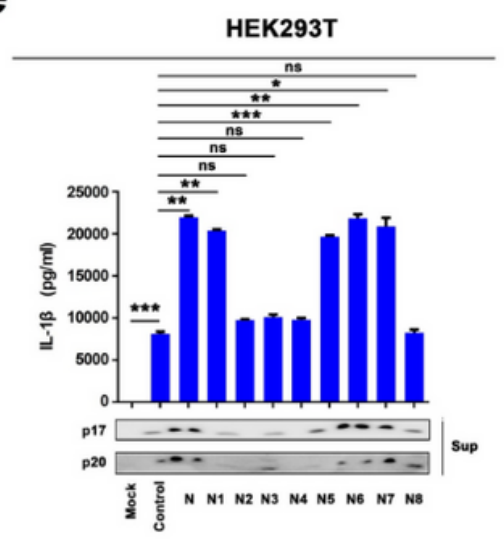

d

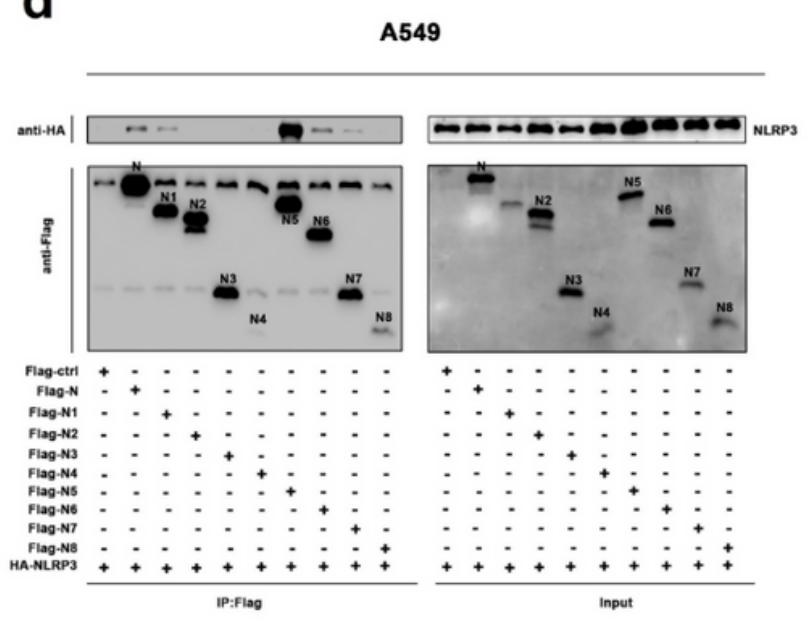

\section{Figure 4}

Sequence 260aa to 340aa of N protein involves in the NLRP3 inflammasome activation. (a) Schematic diagram of wild-type SARS-CoV-2-N protein and truncated mutants N protein (N1 to N8). (b, d) HEK293T 
cells (b) or A549 cells (d) were co-transfected with HA-NLRP3 and Flag-ctrl, Flag-N truncated mutants (N1N8). Cell lysates were immunoprecipitated using anti-Flag antibody, and analyzed using anti-Flag and anti-HA antibody. Cell lysates $(40 \mu \mathrm{g})$ was used as Input. (c) HEK293T cells were co-transfected with HANLRP3 and Flag-N truncated mutants (N1-N8). Cell lysates were immunoprecipitated using anti-HA antibody, IgG antibody was used as negative control, and analyzed using anti-Flag and anti-HA antibody. Cell lysates $(40 \mu \mathrm{g})$ was used as Input. (e) HEK293T cells were co-transfected with plasmids encoding NLRP3, ASC, pro-Casp1 and pro-IL-1 $\beta$, and transfected with plasmids encoding SARS-CoV-2-N protein and truncated mutants $\mathrm{N}$ protein (N1 to N8) for $48 \mathrm{~h}$. Supernatants were analyzed by ELISA for IL-1 $\beta$ and by WB for p17 and p20. Flag-ctrl means pcDNA3.1(+)-3xflag empty plasmid. Mock means untreated cells (e). Control means transfected empty plasmid (e). Date were representative of three independent experiments. Values are mean \pm SEM. $P \leq 0.05(*), P \leq 0.01(* *), P \leq 0.001(\star \star \star)$.

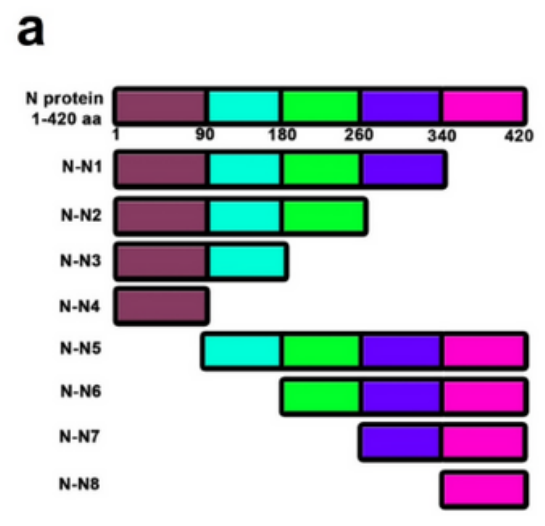

b

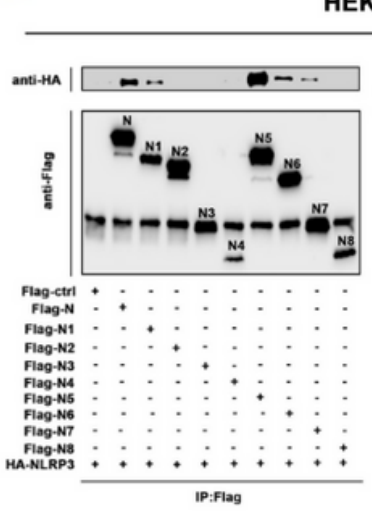

C

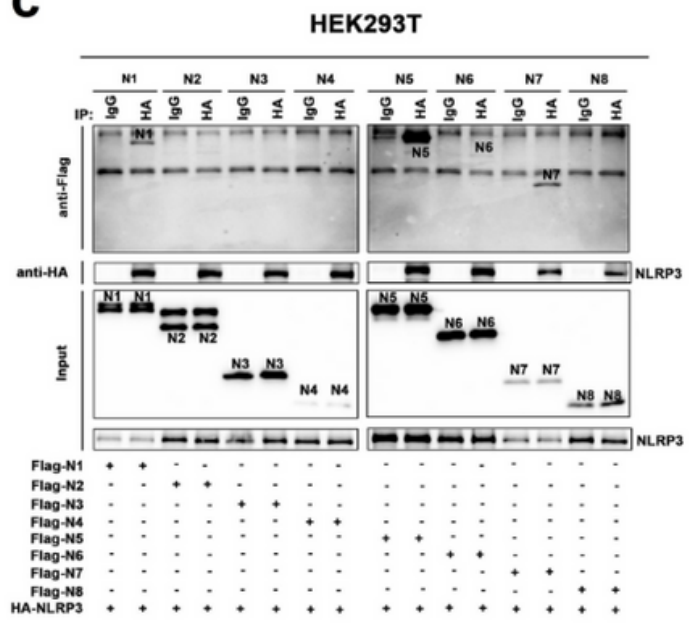

HEK293T

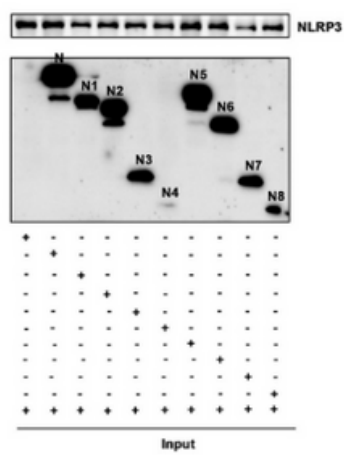

d

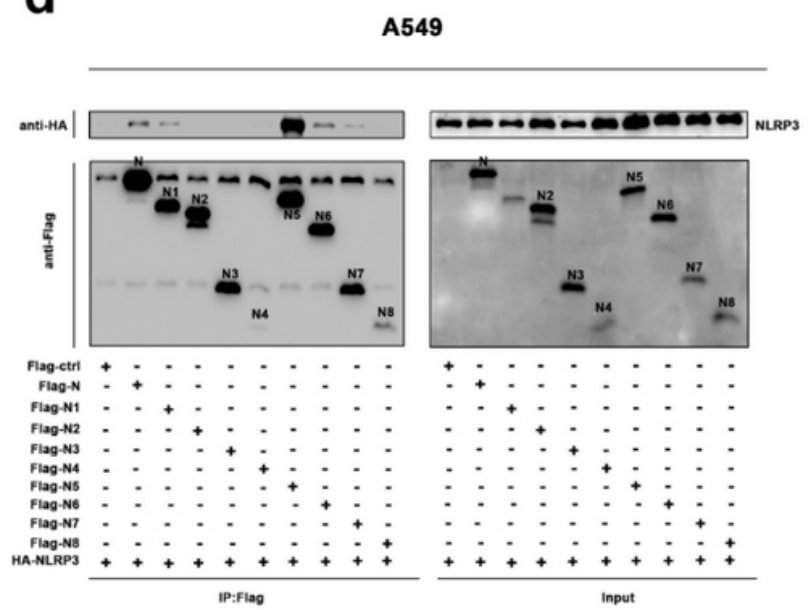

Figure 4

Sequence 260aa to 340aa of N protein involves in the NLRP3 inflammasome activation. (a) Schematic diagram of wild-type SARS-CoV-2-N protein and truncated mutants N protein (N1 to N8). (b, d) HEK293T cells (b) or A549 cells (d) were co-transfected with HA-NLRP3 and Flag-ctrl, Flag-N truncated mutants (N1N8). Cell lysates were immunoprecipitated using anti-Flag antibody, and analyzed using anti-Flag and anti-HA antibody. Cell lysates $(40 \mu \mathrm{g})$ was used as Input. (c) HEK293T cells were co-transfected with HA- 
NLRP3 and Flag-N truncated mutants (N1-N8). Cell lysates were immunoprecipitated using anti-HA antibody, IgG antibody was used as negative control, and analyzed using anti-Flag and anti-HA antibody. Cell lysates $(40 \mu \mathrm{g})$ was used as Input. (e) HEK293T cells were co-transfected with plasmids encoding NLRP3, ASC, pro-Casp1 and pro-IL-1 $\beta$, and transfected with plasmids encoding SARS-CoV-2-N protein and truncated mutants $\mathrm{N}$ protein ( $\mathrm{N} 1$ to $\mathrm{N} 8$ ) for $48 \mathrm{~h}$. Supernatants were analyzed by ELISA for IL-1 $\beta$ and by WB for p17 and p20. Flag-ctrl means pcDNA3.1(+)-3xflag empty plasmid. Mock means untreated cells (e). Control means transfected empty plasmid (e). Date were representative of three independent experiments. Values are mean \pm SEM. $P \leq 0.05(*), P \leq 0.01(* *), P \leq 0.001(* \star *)$. 


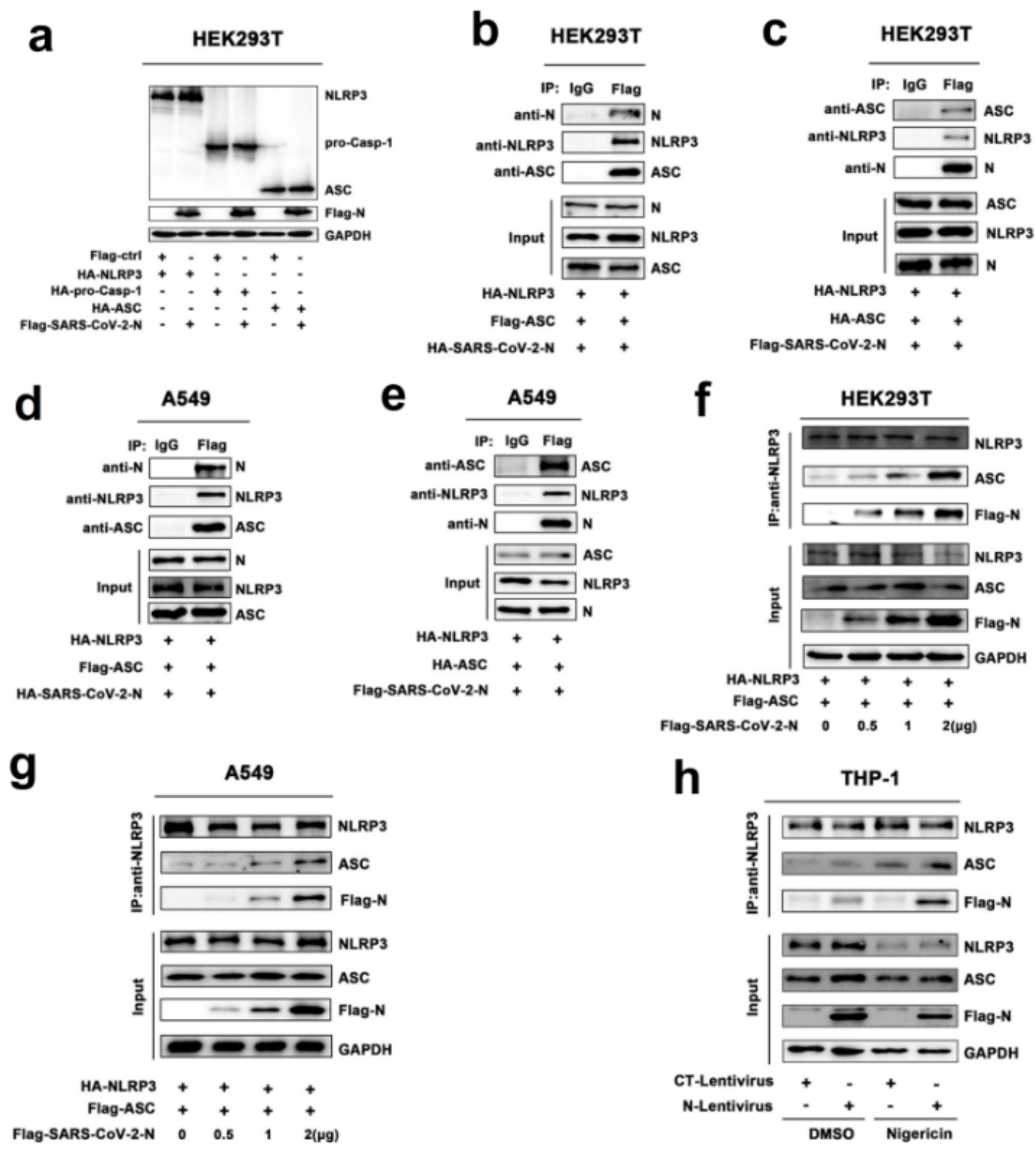

Figure 5

The interaction of NLRP3 with ASC is promoted by SARS-CoV-2 N protein. (a) HEK293T cells were cotransfected with Flag-ctrl or Flag-SARS-CoV-2-N plus HA-NLRP3, HA-pro-Casp1, or HA-ASC for $36 \mathrm{~h}$, the indicated proteins in cell extract were analyzed by WB. (b-e) HEK293T cells (b) or A549 cells (d) were cotransfected with HA-SARS-CoV-2-N, HA-NLRP3 and Flag-ASC for $24 \mathrm{~h}$. Cell lysates were immunoprecipitated using anti-Flag antibody, and analyzed using anti-NLRP3, anti-ASC, and anti-N 
antibody. HEK293T cells (c) or A549 cells (e) were co-transfected with Flag-SARS-CoV-2-N, HA-NLRP3 and HA-ASC for $24 \mathrm{~h}$. Cell lysates were immunoprecipitated using anti-Flag antibody, and analyzed using antiNLRP3, anti-ASC, and anti-N antibody. Cell lysates $(40 \mu \mathrm{g})$ was used as Inputs. (f, g) HEK293T cells (f) or A549 cells ( $\mathrm{g}$ ) were co-transfected with different concentration of Flag-SARS-CoV-2-N plus HA-NLRP3 and Flag-ASC for $24 \mathrm{~h}$. Cell lysates were immunoprecipitated using anti-NLRP3 antibody, and analyzed using anti-NLRP3, anti-ASC, anti-GAPDH and anti-Flag antibody. (h) THP-1 macrophages were stably infected with Lentivirus-CT or Lentivirus- $\mathrm{N}$, and stimulated with $2 \mu \mathrm{M}$ Nigericin or DMSO for $2 \mathrm{~h}$. Cell lysates were immunoprecipitated using anti-NLRP3 antibody, and analyzed using anti-NLRP3, anti-ASC, anti-GAPDH, and anti-N antibody. Flag-ctrl means pcDNA3.1(+)-3×flag empty plasmid. Date were representative of three independent experiments. 


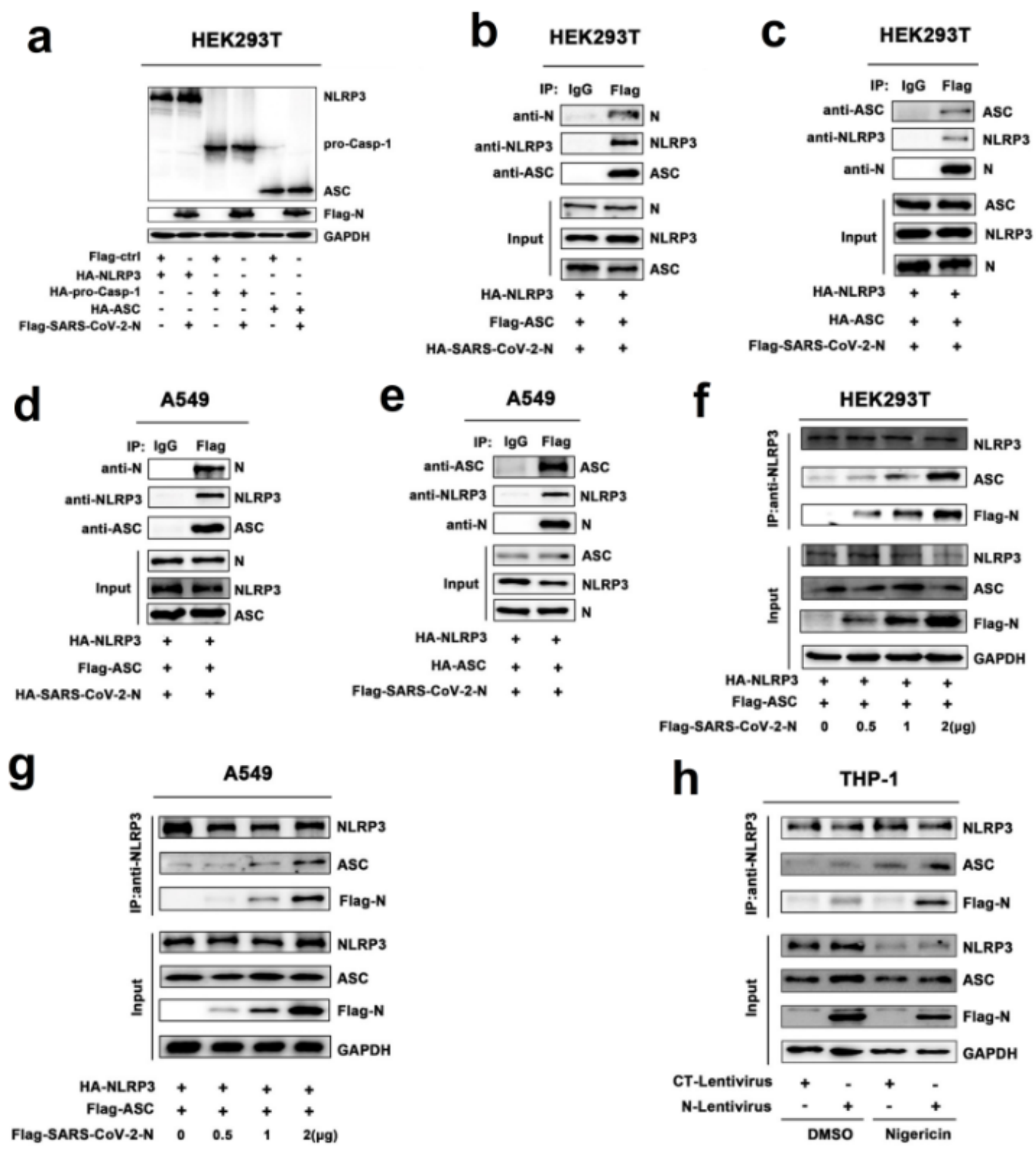

Figure 5

The interaction of NLRP3 with ASC is promoted by SARS-CoV-2 N protein. (a) HEK293T cells were cotransfected with Flag-ctrl or Flag-SARS-CoV-2-N plus HA-NLRP3, HA-pro-Casp1, or HA-ASC for $36 \mathrm{~h}$, the indicated proteins in cell extract were analyzed by WB. (b-e) HEK293T cells (b) or A549 cells (d) were cotransfected with HA-SARS-CoV-2-N, HA-NLRP3 and Flag-ASC for $24 \mathrm{~h}$. Cell lysates were immunoprecipitated using anti-Flag antibody, and analyzed using anti-NLRP3, anti-ASC, and anti-N 
antibody. HEK293T cells (c) or A549 cells (e) were co-transfected with Flag-SARS-CoV-2-N, HA-NLRP3 and HA-ASC for $24 \mathrm{~h}$. Cell lysates were immunoprecipitated using anti-Flag antibody, and analyzed using antiNLRP3, anti-ASC, and anti-N antibody. Cell lysates $(40 \mu \mathrm{g})$ was used as Inputs. (f, g) HEK293T cells (f) or A549 cells ( $\mathrm{g}$ ) were co-transfected with different concentration of Flag-SARS-CoV-2-N plus HA-NLRP3 and Flag-ASC for $24 \mathrm{~h}$. Cell lysates were immunoprecipitated using anti-NLRP3 antibody, and analyzed using anti-NLRP3, anti-ASC, anti-GAPDH and anti-Flag antibody. (h) THP-1 macrophages were stably infected with Lentivirus-CT or Lentivirus- $\mathrm{N}$, and stimulated with $2 \mu \mathrm{M}$ Nigericin or DMSO for $2 \mathrm{~h}$. Cell lysates were immunoprecipitated using anti-NLRP3 antibody, and analyzed using anti-NLRP3, anti-ASC, anti-GAPDH, and anti-N antibody. Flag-ctrl means pcDNA3.1(+)-3×flag empty plasmid. Date were representative of three independent experiments. 
a

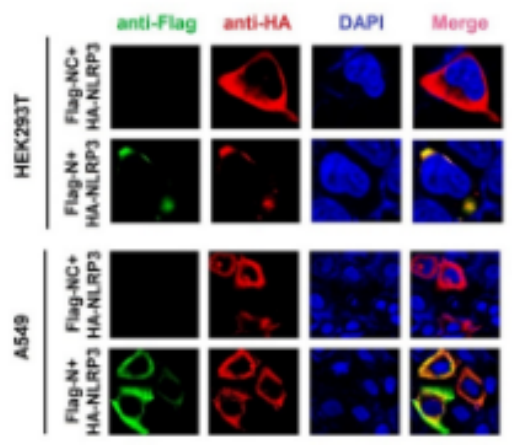

d

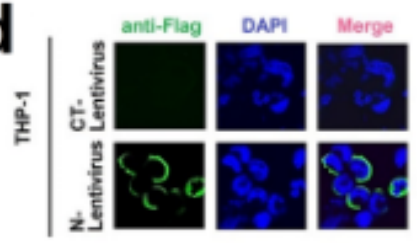

f

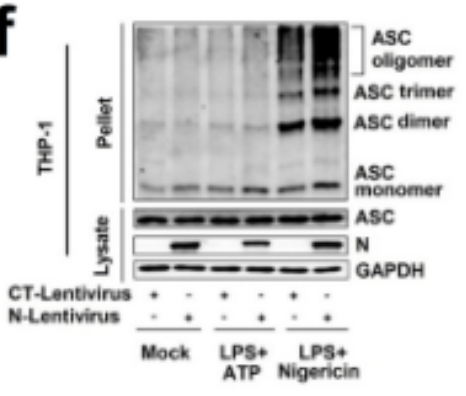

i

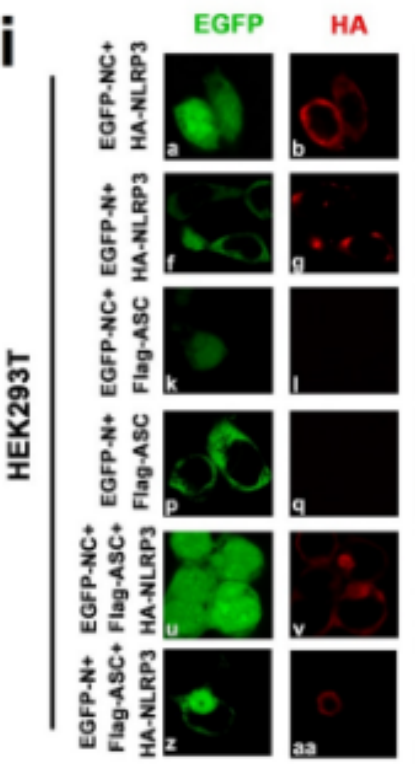

b
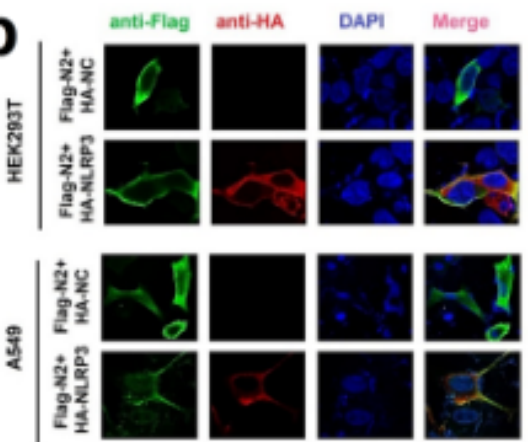

e

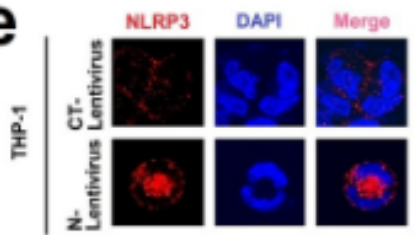

g

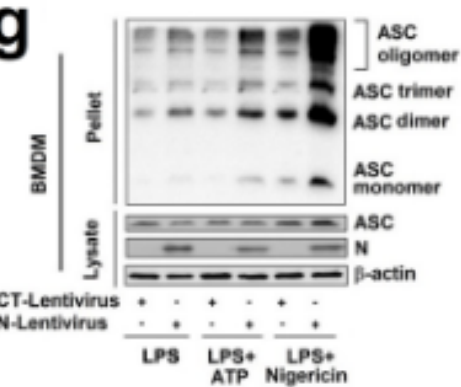

C

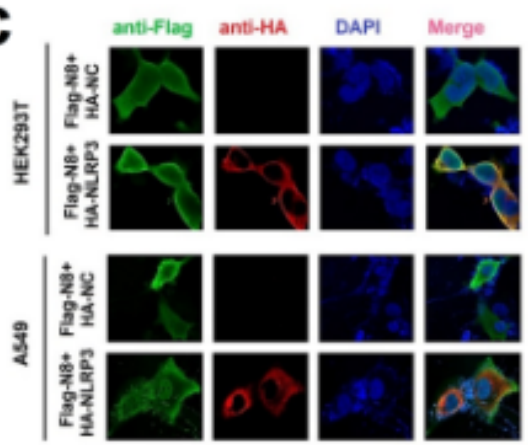

h

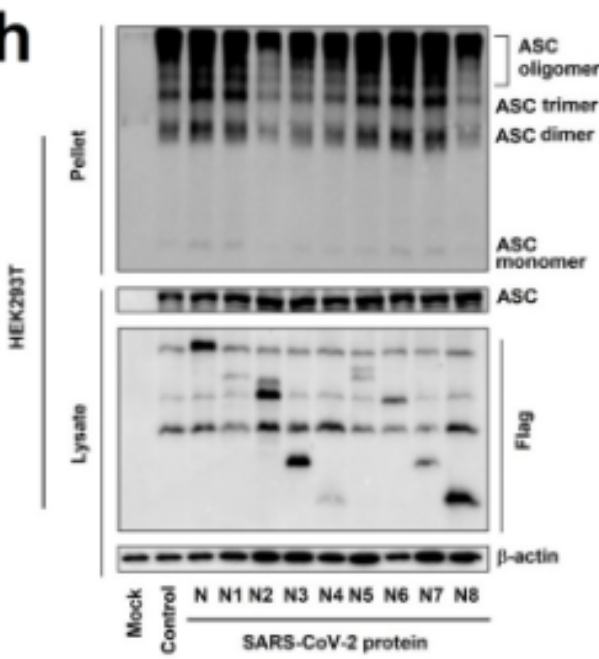

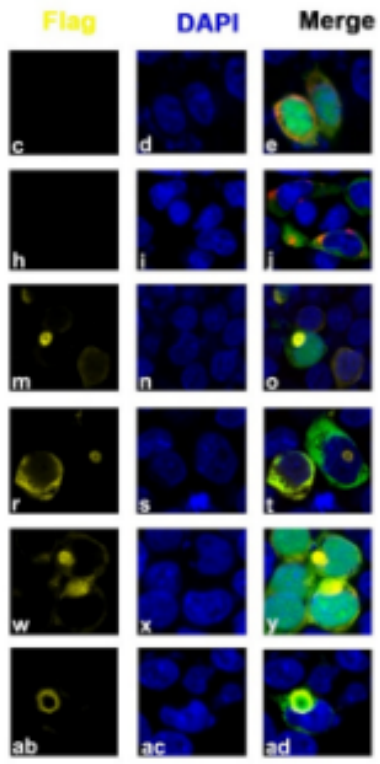
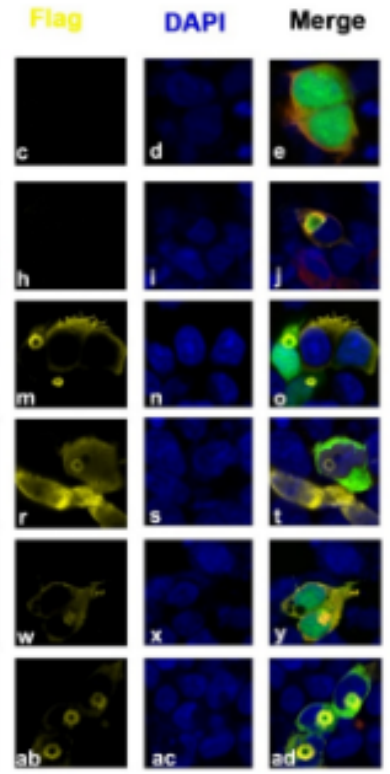

Figure 6

The assemble of the NLRP3 inflammasome is facilitated by SARS-CoV-2 N protein. (a) HEK293T cells (top) or A549 cells (bottom) were transfected with Flag-NC/HA-NLRP3 or Flag-N/HA-NLRP3 for $24 \mathrm{~h}$. The sub-cellular locations of NLRP3 (red), Nucleus marker DAPI (blue) and SARS-CoV-2-N (green) were visualized with confocal microscopy. (b) HEK293T cells (top) or A549 cells (bottom) were transfected with Flag-N2/HA-NC or Flag-N2/HA-NLRP3 for $24 \mathrm{~h}$. The sub-cellular locations of NLRP3 (red), Nucleus 
marker DAPI (blue) and SARS-CoV-2-N8 (green) were visualized with confocal microscopy. (c) HEK293T cells (top) or A549 cells (bottom) were transfected with Flag-N8/HA-NC or Flag-N8/HA-NLRP3 for $24 \mathrm{~h}$. The sub-cellular locations of NLRP3 (red), Nucleus marker DAPI (blue) and SARS-CoV-2-N8 (green) were visualized with confocal microscopy. (d, e) PMA-differentiated THP-1 macrophages were stably infected with Lentivirus-CT or Lentivirus-N. The sub-cellular locations of SARS-CoV-2-N (green, d) Nucleus marker DAPI (blue) and NLRP3 (red, e), were visualized with confocal microscopy. (f) THP-1 macrophages were stably infected with Lentivirus-CT or Lentivirus- $N$, and stimulated by LPS $(1 \mu \mathrm{g} / \mathrm{ml})$ plus ATP $(2.5 \mathrm{mM})$ or LPS $(1 \mu \mathrm{g} / \mathrm{ml})$ plus Nigericin $(2 \mu \mathrm{M})$. ASC oligomerisation was analyzed by immunoblotting. (g) GM-CSF differentiated mice BMDMs were infected with Lentivirus-CT or Lentivirus-N and stimulated with LPS (1 $\mu \mathrm{g} / \mathrm{ml})$, LPS $(1 \mu \mathrm{g} / \mathrm{ml})$ plus ATP $(2.5 \mathrm{mM})$ or LPS $(1 \mu \mathrm{g} / \mathrm{ml})$ plus Nigericin $(2 \mu \mathrm{M})$. ASC oligomerisation was analyzed by immunoblotting. (h) HEK293T cells were co-transfected with plasmids encoding NLRP3, ASC, pro-Casp1 or pro-IL-1 $\beta$, and transfected with plasmids encoding SARS-CoV-2-N protein and truncated mutants N protein (N1 to N8) for 48h, ASC oligomerisation was analyzed by immunoblotting. (i, j) HEK293T cells (i) and A549 cells (j) were co-transfected with GFP/HA-NLRP3, GFP-N/HA-NLRP3, GFP/Flag-ASC, GFP-N/Flag-ASC, GFP/HA-NLRP3/Flag-ASC, or GFP-N/HA-NLRP3/Flag-ASC for $24 \mathrm{~h}$. The sub-cellular locations of HA-tagged NLRP3 (red), Flag-tagged ASC (yellow), GFP-tagged N (green), and nucleus marker DAPI (blue) were visual with confocal microscopy. Flag-NC or HA-NC means pcDNA3.1(+)-3×flag or pCAGGS-HA empty plasmid (a-c), Mock means untreated cells $(f, h)$, Control means transfected empty plasmid ( $h$ ), GFP-NC means pEGFP-C1 empty plasmid (i, j). Date were representative of three independent experiments. 
a

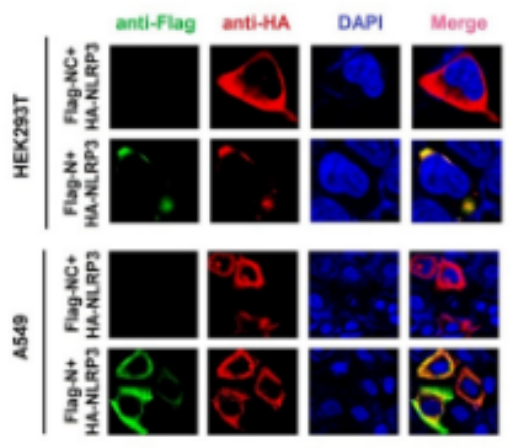

d

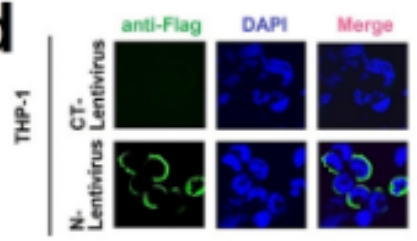

f

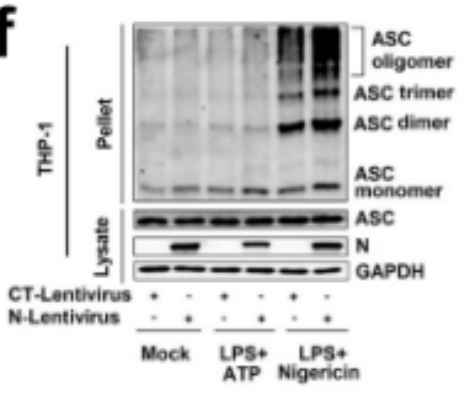

i

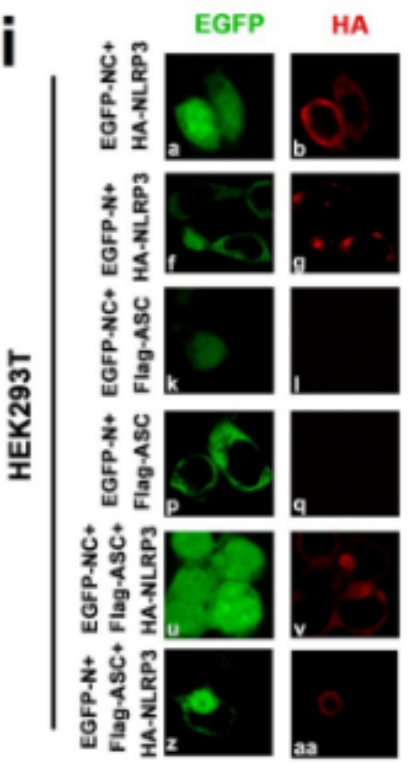

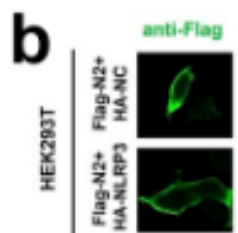

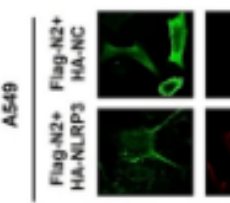

e

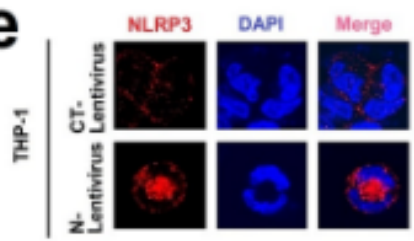

g

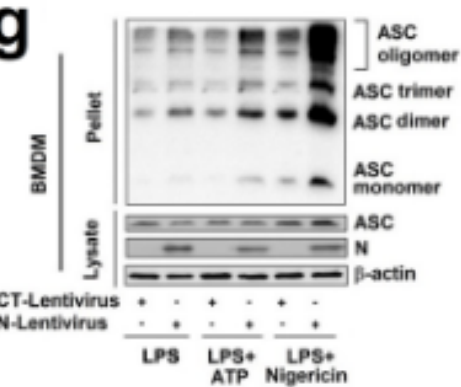

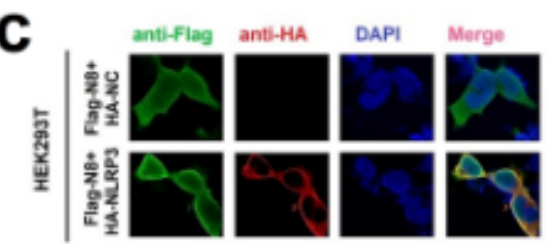
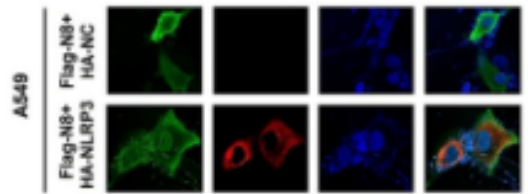

h

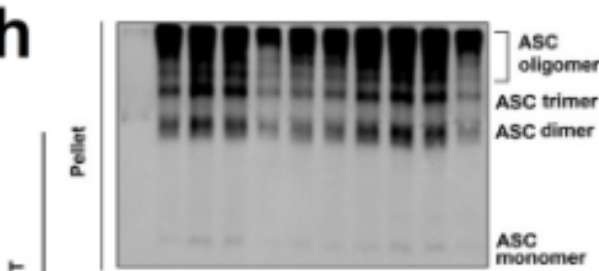

点
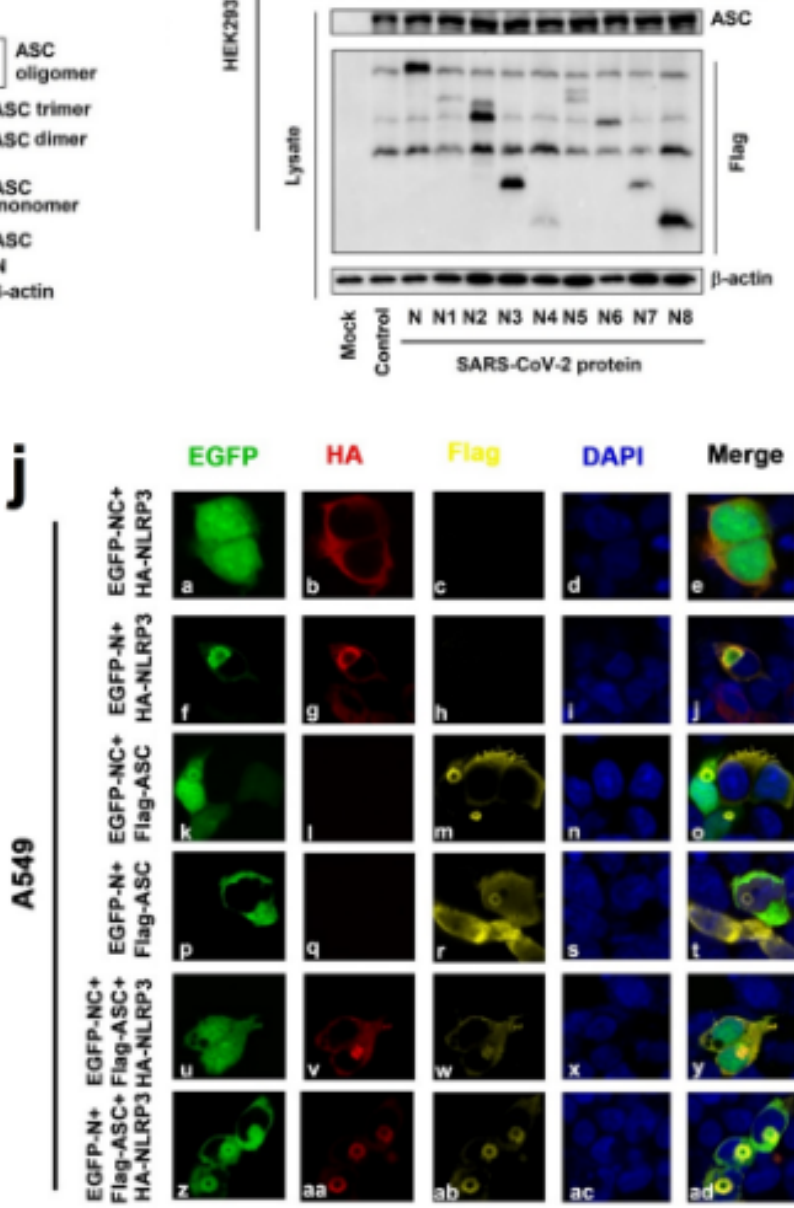
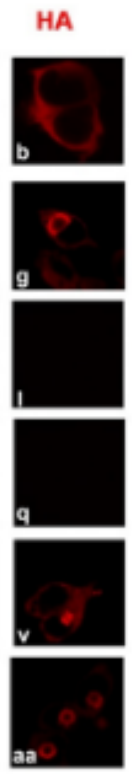
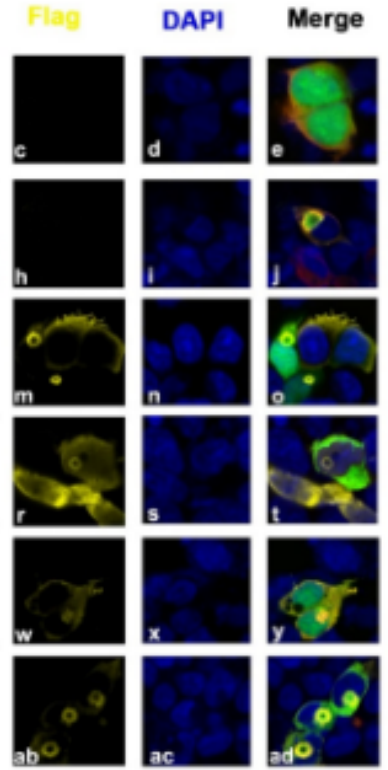

Figure 6

The assemble of the NLRP3 inflammasome is facilitated by SARS-CoV-2 N protein. (a) HEK293T cells (top) or A549 cells (bottom) were transfected with Flag-NC/HA-NLRP3 or Flag-N/HA-NLRP3 for $24 \mathrm{~h}$. The sub-cellular locations of NLRP3 (red), Nucleus marker DAPI (blue) and SARS-CoV-2-N (green) were visualized with confocal microscopy. (b) HEK293T cells (top) or A549 cells (bottom) were transfected with Flag-N2/HA-NC or Flag-N2/HA-NLRP3 for $24 \mathrm{~h}$. The sub-cellular locations of NLRP3 (red), Nucleus 
marker DAPI (blue) and SARS-CoV-2-N8 (green) were visualized with confocal microscopy. (c) HEK293T cells (top) or A549 cells (bottom) were transfected with Flag-N8/HA-NC or Flag-N8/HA-NLRP3 for $24 \mathrm{~h}$. The sub-cellular locations of NLRP3 (red), Nucleus marker DAPI (blue) and SARS-CoV-2-N8 (green) were visualized with confocal microscopy. (d, e) PMA-differentiated THP-1 macrophages were stably infected with Lentivirus-CT or Lentivirus-N. The sub-cellular locations of SARS-CoV-2-N (green, d) Nucleus marker DAPI (blue) and NLRP3 (red, e), were visualized with confocal microscopy. (f) THP-1 macrophages were stably infected with Lentivirus-CT or Lentivirus- $N$, and stimulated by LPS $(1 \mu \mathrm{g} / \mathrm{ml})$ plus ATP $(2.5 \mathrm{mM})$ or LPS $(1 \mu \mathrm{g} / \mathrm{ml})$ plus Nigericin $(2 \mu \mathrm{M})$. ASC oligomerisation was analyzed by immunoblotting. (g) GM-CSF differentiated mice BMDMs were infected with Lentivirus-CT or Lentivirus-N and stimulated with LPS (1 $\mu \mathrm{g} / \mathrm{ml})$, LPS $(1 \mu \mathrm{g} / \mathrm{ml})$ plus ATP $(2.5 \mathrm{mM})$ or LPS $(1 \mu \mathrm{g} / \mathrm{ml})$ plus Nigericin $(2 \mu \mathrm{M})$. ASC oligomerisation was analyzed by immunoblotting. (h) HEK293T cells were co-transfected with plasmids encoding NLRP3, ASC, pro-Casp1 or pro-IL-1 $\beta$, and transfected with plasmids encoding SARS-CoV-2-N protein and truncated mutants N protein (N1 to N8) for 48h, ASC oligomerisation was analyzed by immunoblotting. (i, j) HEK293T cells (i) and A549 cells (j) were co-transfected with GFP/HA-NLRP3, GFP-N/HA-NLRP3, GFP/Flag-ASC, GFP-N/Flag-ASC, GFP/HA-NLRP3/Flag-ASC, or GFP-N/HA-NLRP3/Flag-ASC for $24 \mathrm{~h}$. The sub-cellular locations of HA-tagged NLRP3 (red), Flag-tagged ASC (yellow), GFP-tagged N (green), and nucleus marker DAPI (blue) were visual with confocal microscopy. Flag-NC or HA-NC means pcDNA3.1(+)-3×flag or pCAGGS-HA empty plasmid (a-c), Mock means untreated cells $(f, h)$, Control means transfected empty plasmid ( $h$ ), GFP-NC means pEGFP-C1 empty plasmid (i, j). Date were representative of three independent experiments. 
a

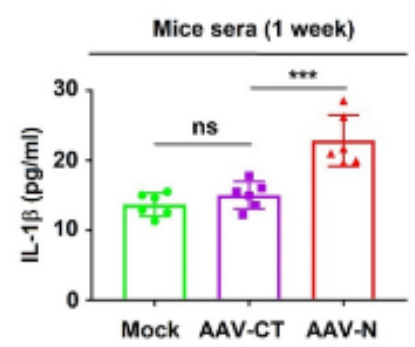

b

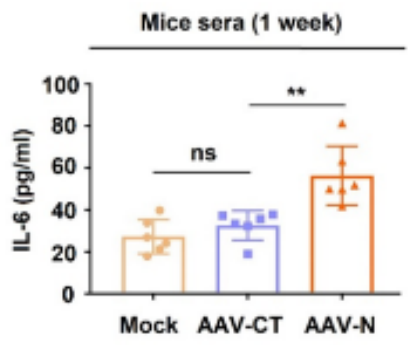

C

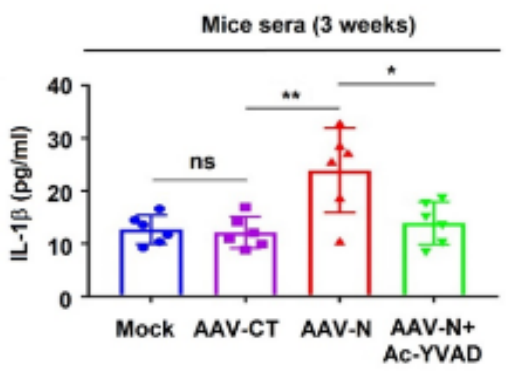

d

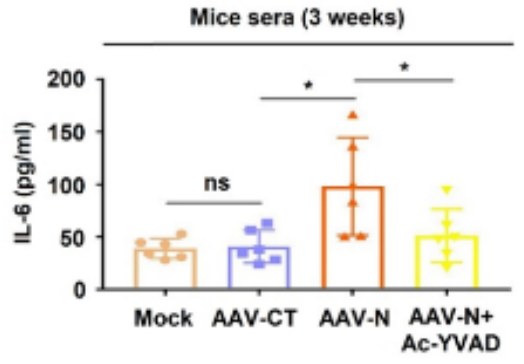

e

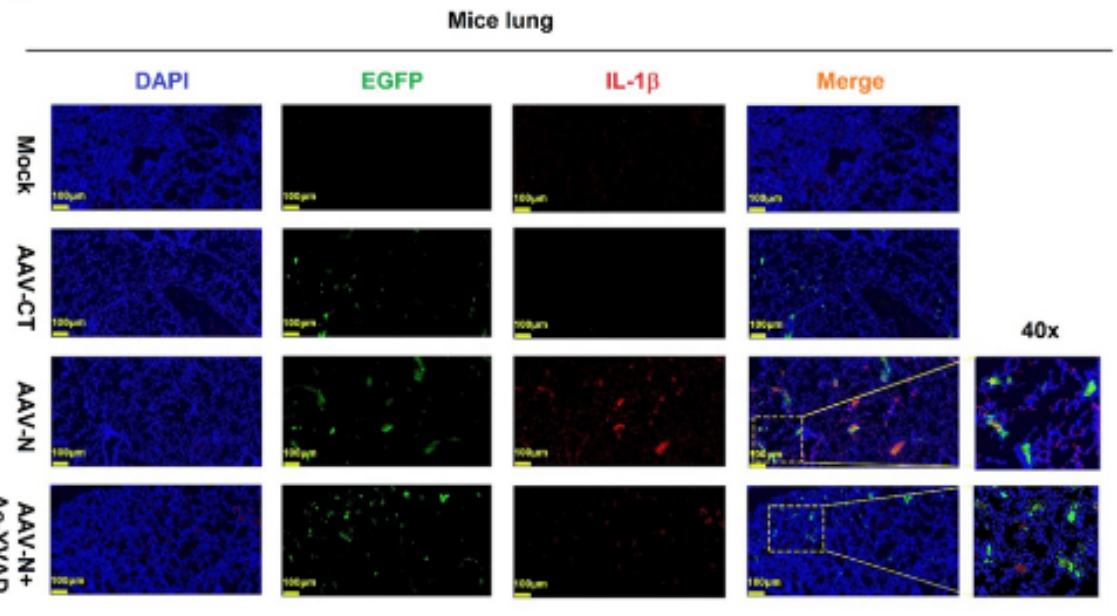

f

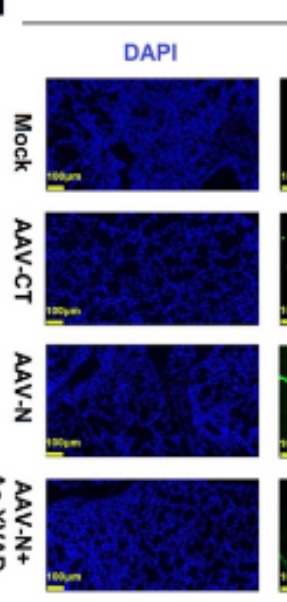

Mice lung
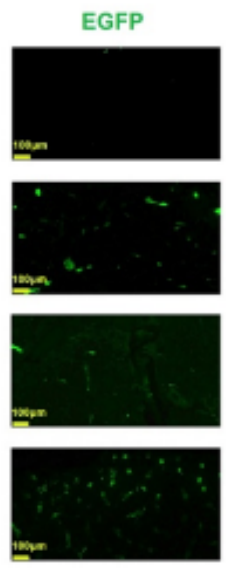

IL-6 lung
IL
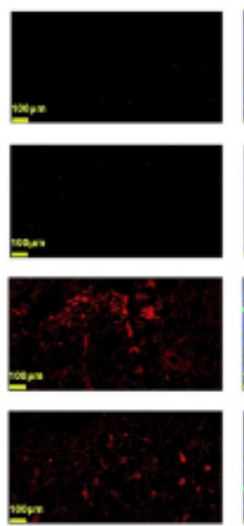
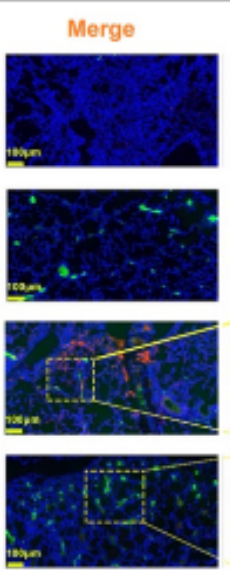

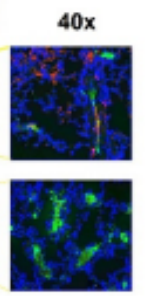

g

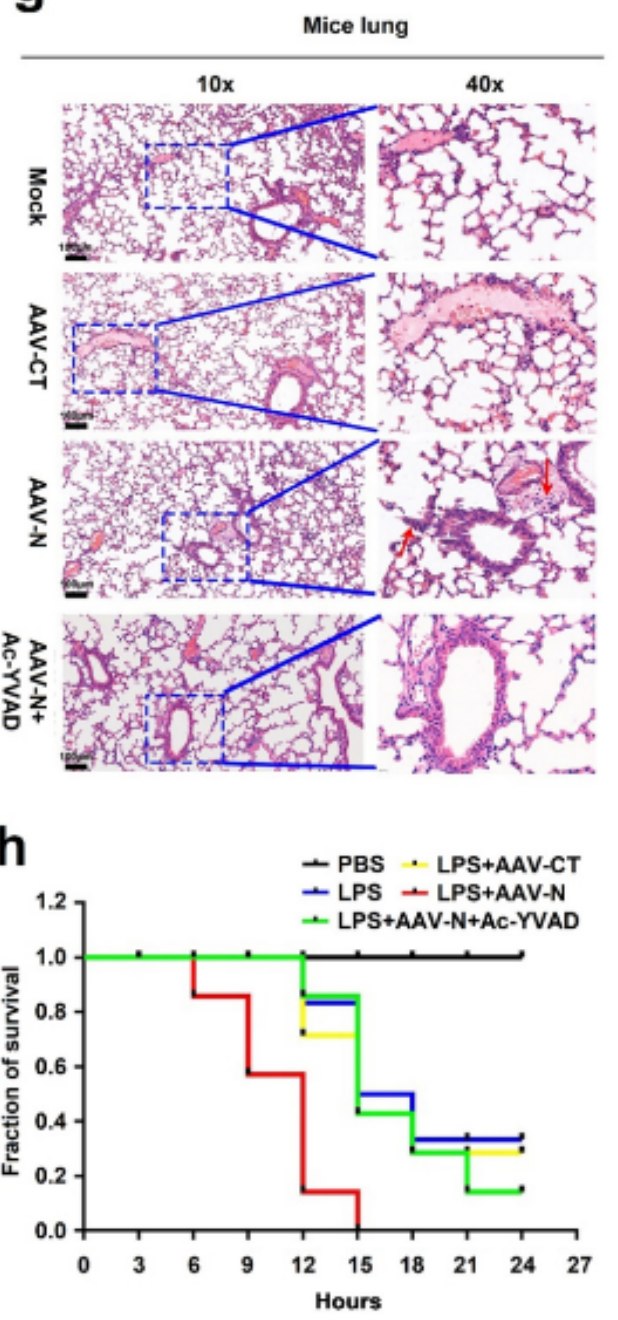

\section{Figure 7}

SARS-CoV-2 N protein induces mice lung injury via activating the NLRP3 inflammasome. (a-g) C57BL/6 genetic background mice were tail vein injection with $300 \mu$ containing $5 \times 1011 \mathrm{vg}$ of AAV-Lung-EGFP $(\mathrm{n}=8)$ or AAV-Lung-N $(\mathrm{n}=16)$, after two weeks, treated with Ac-YVAD-cmk (8 $\mathrm{mg} / \mathrm{kg})$ by intraperitoneal injection for AAV-Lung-N ( $n=8)$ mice. (a-d) Serum was collected at one week and three weeks for each group from the orbit. IL-1 $\beta$ ( $a$ and $c$ ) or IL-6 ( $b$ and $d$ ) in the sera was measured by ELISA. Points represent the value of each serum samples. $(\mathrm{e}-\mathrm{g})$ At three weeks, mice were euthanized, and Lung were collected. $(e, f)$ Histoimmunofluorescence analysis of IL-1 $\beta$ (e, red) or IL-6 (f, red) in the lung after AAV-CT or AAV9-N 
infection. Scale bar is $100 \mu \mathrm{m}(10 \mathrm{x})$ or $50 \mu \mathrm{m}(40 \mathrm{x})$. (g) Histopathology analysis of lung after AAV-CT or AAV-N infection. Red arrows indicated the infiltrated inflammatory cells. Scale bar is $100 \mu \mathrm{m}(10 \times)$ or 50 $\mu \mathrm{m}(40 \mathrm{x})$. (h) After four weeks, pretreated with DMSO for AAV-Lung-N ( $\mathrm{n}=7)$ mice or Ac-YVAD-cmk (8 $\mathrm{mg} / \mathrm{kg}$ ) for another AAV-Lung-N ( $\mathrm{n}=7)$ mice. After 30 min, mock group $(\mathrm{n}=6)$, AAV-Lung-EGFP $(\mathrm{n}=7)$ group, AAV-Lung-N $(n=7)$ group and another AAV-Lung- $N(n=7)$ group were treated with LPS $(30 \mathrm{mg} / \mathrm{kg})$ by intraperitoneal injection. Another mock group $(n=4)$ was intraperitoneal injected with PBS. Then the mice survival rates were evaluated every three hours posttreatment. Mock means inject the same dose of PBS as other groups $(\mathrm{a}-\mathrm{g})$. Date were representative of two independent experiments. Values are mean \pm SEM. $P \leq 0.05(*), P \leq 0.01(* *), P \leq 0.001{ }^{(* *)}$.

a

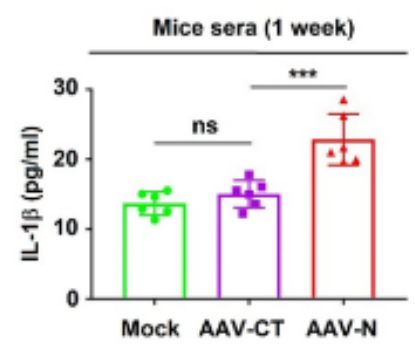

b

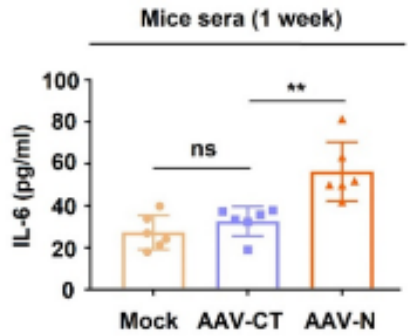

C

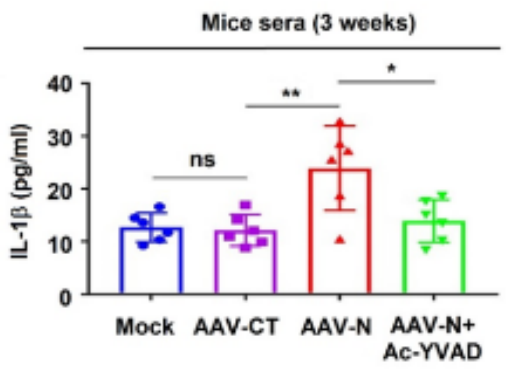

d

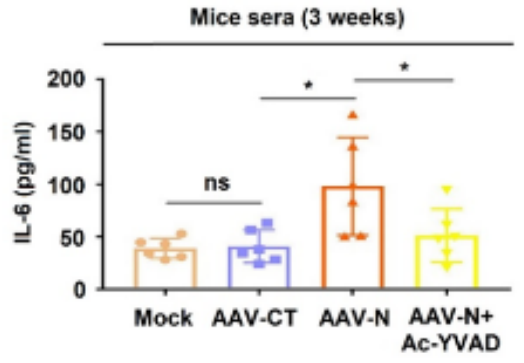

e

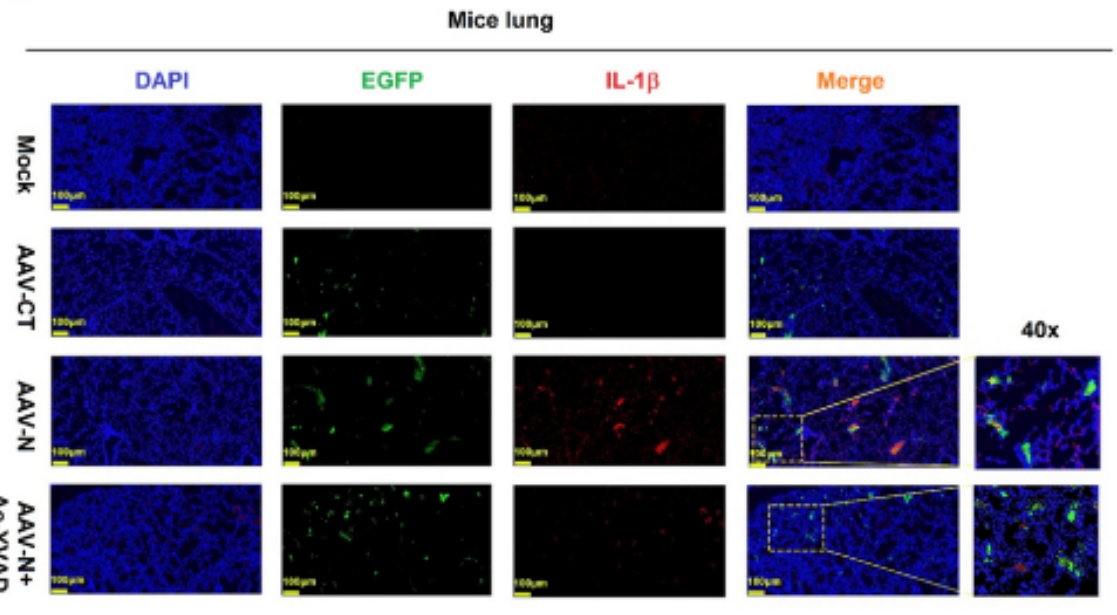

f

f
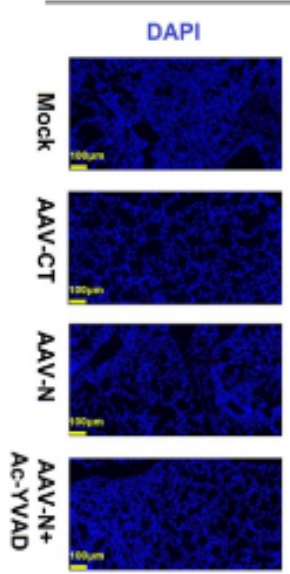

Mice lung
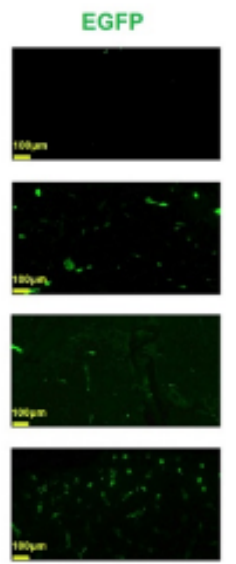

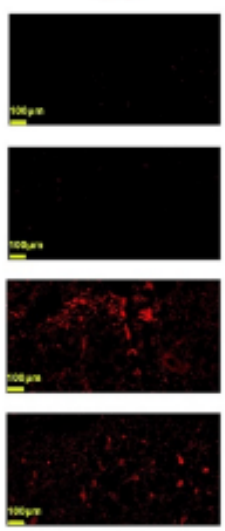

Merge
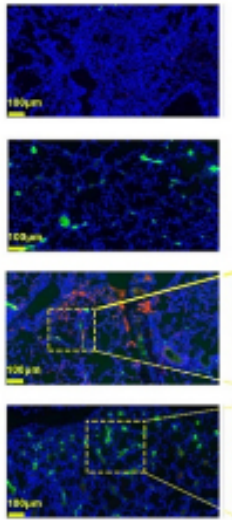

g

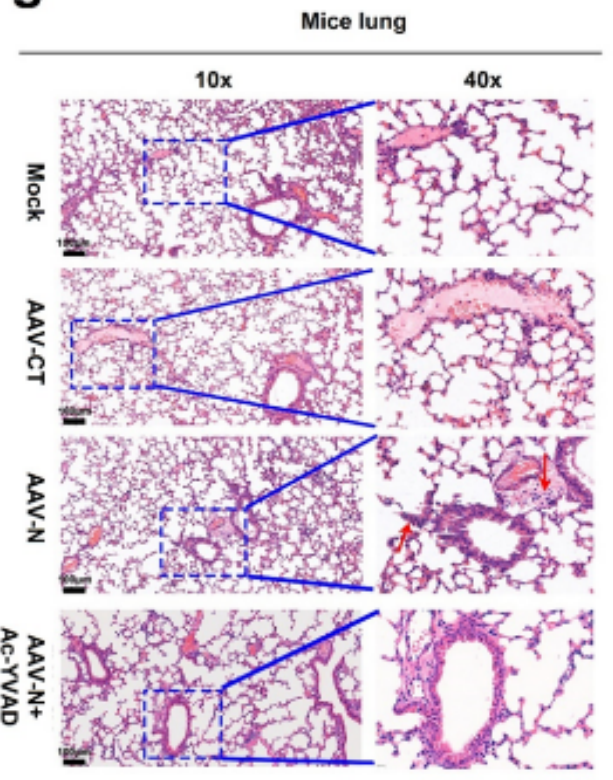

h

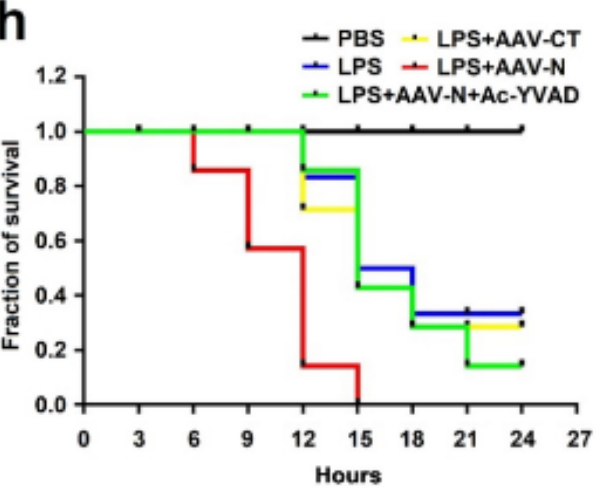




\section{Figure 7}

SARS-CoV-2 N protein induces mice lung injury via activating the NLRP3 inflammasome. (a-g) C57BL/6 genetic background mice were tail vein injection with $300 \mu$ containing $5 \times 1011 \mathrm{vg}$ of AAV-Lung-EGFP $(\mathrm{n}=8)$ or AAV-Lung-N $(\mathrm{n}=16)$, after two weeks, treated with Ac-YVAD-cmk (8 mg/kg) by intraperitoneal injection for AAV-Lung-N ( $n=8)$ mice. (a-d) Serum was collected at one week and three weeks for each group from the orbit. IL-1 $\beta$ ( $a$ and $c$ ) or IL-6 (b and d) in the sera was measured by ELISA. Points represent the value of each serum samples. $(\mathrm{e}-\mathrm{g})$ At three weeks, mice were euthanized, and Lung were collected. $(e, f)$ Histoimmunofluorescence analysis of IL-1 $\beta$ (e, red) or IL-6 (f, red) in the lung after AAV-CT or AAV9-N infection. Scale bar is $100 \mu \mathrm{m}(10 \times)$ or $50 \mu \mathrm{m}(40 \times)$. (g) Histopathology analysis of lung after AAV-CT or AAV-N infection. Red arrows indicated the infiltrated inflammatory cells. Scale bar is $100 \mu \mathrm{m}(10 \mathrm{x})$ or 50 $\mu \mathrm{m}(40 \times)$. (h) After four weeks, pretreated with DMSO for AAV-Lung-N ( $\mathrm{n}=7)$ mice or Ac-YVAD-cmk (8 $\mathrm{mg} / \mathrm{kg})$ for another AAV-Lung-N ( $\mathrm{n}=7)$ mice. After 30 min, mock group $(\mathrm{n}=6)$, AAV-Lung-EGFP $(\mathrm{n}=7)$ group, AAV-Lung-N $(n=7)$ group and another AAV-Lung-N $(n=7)$ group were treated with LPS $(30 \mathrm{mg} / \mathrm{kg})$ by intraperitoneal injection. Another mock group $(n=4)$ was intraperitoneal injected with PBS. Then the mice survival rates were evaluated every three hours posttreatment. Mock means inject the same dose of PBS as other groups $(\mathrm{a}-\mathrm{g})$. Date were representative of two independent experiments. Values are mean \pm SEM. $P \leq 0.05(*), P \leq 0.01\left(^{(* *)}, P \leq 0.001{ }^{(* *}\right)$.
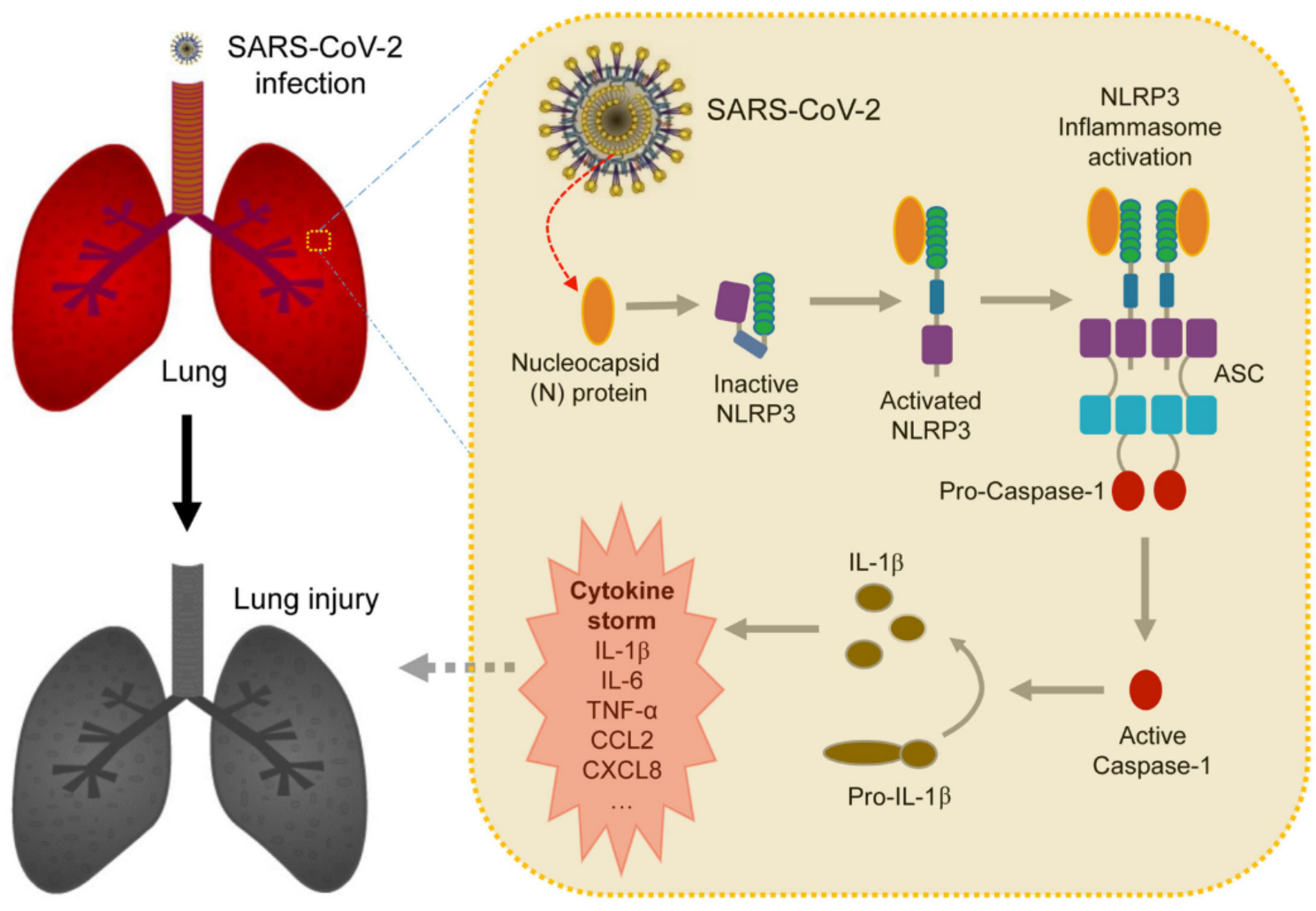


\section{Figure 8}

A proposed model in which SARS-CoV-2 N protein induces lung injury by activating NLRP3 inflammasome. During SARS-CoV-2 infection, the nucleocapsid protein $(\mathrm{N})$ could directly interact with NLRP3 to promote the assembly and activation of NLRP3 inflammasome, thus leading to the production of a large number of inflammatory factors (like IL-1 $\beta$, IL-6, TNF-a, CCL2, and CCL8) and the occurrence of lung injury in mice.

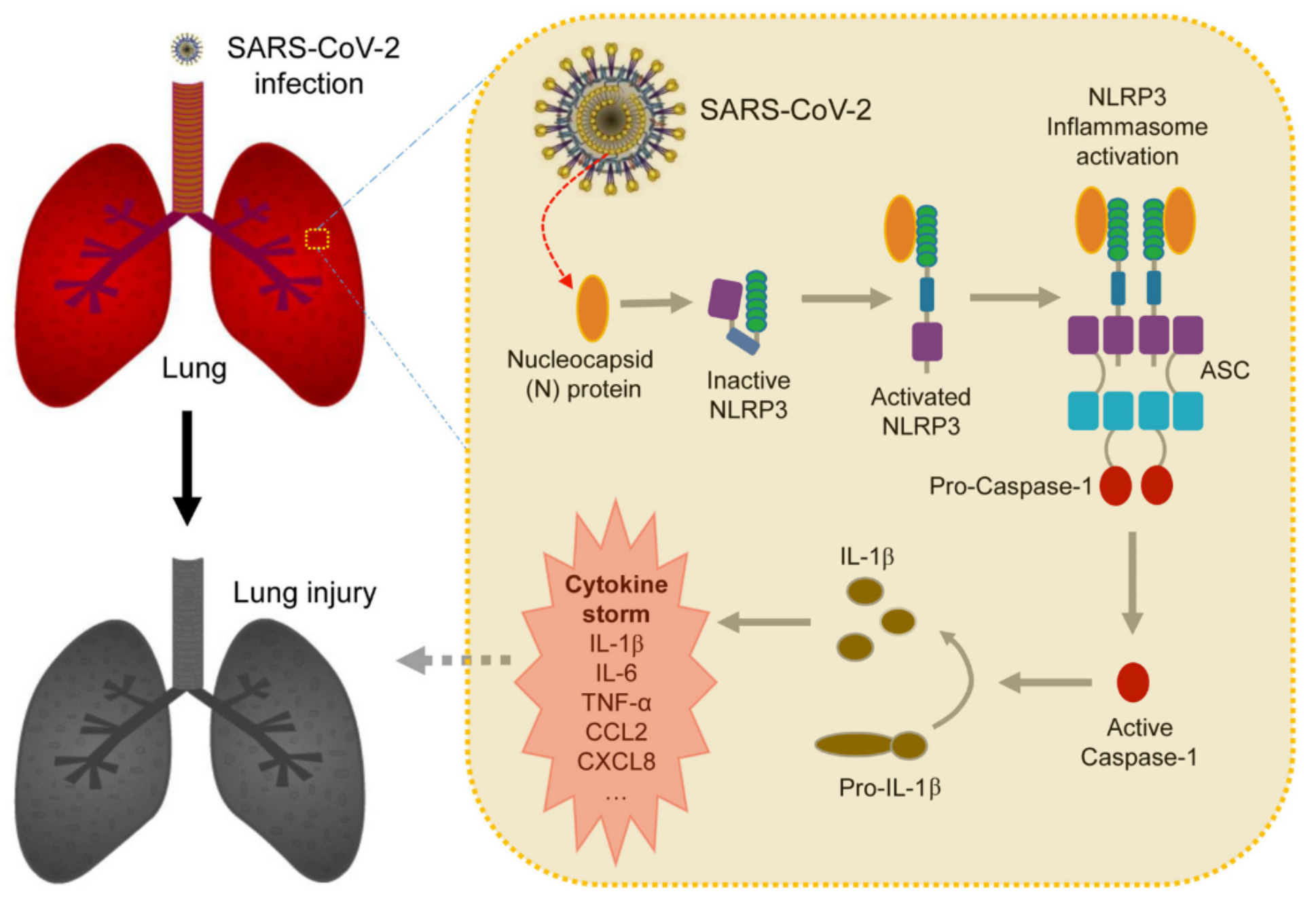

Figure 8

A proposed model in which SARS-CoV-2 $\mathrm{N}$ protein induces lung injury by activating NLRP3 inflammasome. During SARS-CoV-2 infection, the nucleocapsid protein $(\mathrm{N})$ could directly interact with NLRP3 to promote the assembly and activation of NLRP3 inflammasome, thus leading to the production of a large number of inflammatory factors (like IL-1 $\beta$, IL-6, TNF-a, CCL2, and CCL8) and the occurrence of lung injury in mice. 